\title{
Genetic Analysis of Water Use Efficiency in Rice (Oryza sativa L.) at the Leaf Level
}

\author{
Dominique This • Jonathan Comstock • \\ Brigitte Courtois • Yunbi Xu • Nourollah Ahmadi • \\ Wendy M. Vonhof • Christine Fleet • Tim Setter • \\ Susan McCouch
}

Received: 10 September 2009/Accepted: 11 January 2010/Published online: 18 February 2010

(C) Springer Science+Business Media, LLC 2010

\begin{abstract}
Carbon isotope discrimination $\left(\Delta^{13} C\right)$ is considered as an index of leaf-level water use efficiency, an important objective for plant breeders seeking to conserve water resources. We report in rice a genetic analysis for $\Delta^{13} \mathrm{C}$, leaf structural parameters, gas exchange, stomatal conductance, and leaf abscisic acid (ABA) concentrations. Doubled haploid and recombinant inbred populations, both derived from the cross IR64 $\times$ Azucena, were used for quantitative trait locus (QTL) analysis following greenhouse experiments. $\Delta^{13} \mathrm{C}$ QTLs on the long arms of chromosomes 4 and 5 were co-
\end{abstract}

Electronic supplementary material The online version of this article (doi:10.1007/s12284-010-9036-9) contains supplementary material, which is available to authorized users.

\section{This}

Montpellier SupAgro, UMR DAP,

CIRAD TA 40/03, Avenue Agropolis,

34398 Montpellier Cedex 5, France

D. This $\cdot$ J. Comstock $\cdot$ Y. Xu $\cdot$ T. Setter $\cdot$ S. McCouch $(\triangle)$

Department of Plant Breeding and Genetics, Cornell University,

Ithaca, NY 14853, USA

e-mail: srm4@cornell.edu

B. Courtois $\cdot$ N. Ahmadi

Department Bios, CIRAD,

CIRAD TA 40/03, Avenue Agropolis,

34398 Montpellier Cedex 5, France

W. M. Vonhof $\cdot$ C. Fleet

Boyce Thompson Institute for Plant

Research at Cornell University,

Ithaca, NY 14853, USA

Y. Xu

CIMMYT,

Apdo. Postal 6-641,

Mexico, D.F. 06600, Mexico localized with QTLs associated with leaf blade width, length, and flatness, while a QTL cluster for $\Delta^{13} \mathrm{C}$, photosynthesis parameters, and ABA was observed in the near-centromeric region of chromosome 4 . These results are consistent with phenotypic correlations and suggest that genetic variation in carbon assimilation and stomatal conductance contribute to the genetic variation for $\Delta^{13} \mathrm{C}$ in this population.

Keywords Water use efficiency - Carbon isotope discrimination - Oryza sativa

\section{Introduction}

The use of water by human populations has increased dramatically over time, with irrigated agriculture representing up to $85 \%$ of total human water consumption (Gleick 2003). Breeding for improved water use efficiency (WUE) of both rain-fed and irrigated crops is imperative in the face of world population expansion. Condon et al. (2004) suggested three ways to mitigate water use by crop plants: (1) allow more available water to pass directly through the crop rather than allowing it to evaporate from an irrigated soil surface, (2) acquire more biomass in exchange for a given amount of water transpired by the crop, (3) increase the harvest index by partitioning a greater proportion of biomass into the harvested product. The first of these strategies is largely a crop management issue, but all of them can be approached through genetic improvement. In this study, we will focus on acquiring more biomass in exchange for a given amount of water transpired by the crop and will refer to this as water use efficiency.

Leaf water use efficiency can be expressed as the ratio of carbon gained in photosynthesis (A) by water used in 
transpiration (E). This physiological trait can be evaluated, at least for $\mathrm{C} 3$ species, by carbon isotope discrimination, i.e., the ${ }^{13} \mathrm{C} /{ }^{12} \mathrm{C}$ ratio in plant material relative to the same ratio in the air in which plants are growing. Carbon isotope discrimination has been defined by Farquhar and Richards (1984) as:

$\Delta^{13} \mathrm{C}=\left[\left(R_{\mathrm{a}} / R_{\mathrm{p}}\right)-1\right] \times 1,000$

where $R_{\mathrm{a}}$ is the value of ${ }^{13} \mathrm{C} /{ }^{12} \mathrm{C}$ ratio in the atmosphere and $R_{\mathrm{p}}$ is the value of ${ }^{13} \mathrm{C} /{ }^{12} \mathrm{C}$ ratio in the plant material. Fractionations associated with $\mathrm{CO}_{2}$ diffusion into intracellular airspaces and $\mathrm{CO}_{2}$ carboxylation by RuBisCO represent dominant processes in carbon isotope discrimination. Farquhar and Richards (1984) proposed an approximate relationship between $\Delta^{13} \mathrm{C}$ and $\mathrm{C}_{\mathrm{i}} / \mathrm{C}_{\mathrm{a}}$ (ratio of internal to air $\mathrm{CO}_{2}$ concentration):

$\Delta^{13} \mathrm{C}=\mathrm{a}+(\mathrm{b}-\mathrm{a}) \mathrm{C}_{\mathrm{i}} / \mathrm{C}_{\mathrm{a}}$.

$\Delta{ }^{13} \mathrm{C}$ is therefore positively related to $\mathrm{C}_{\mathrm{i}} / \mathrm{C}_{\mathrm{a}}$ and negatively to $\mathrm{A} / \mathrm{E}$.

In Australia, the development of wheat breeding lines that combine high-yield with low- $\Delta{ }^{13} \mathrm{C}$ recently led to the release of two commercial cultivars, "Drysdale" and "Rees," both of which provide some yield advantage in the lower range of wheat yields (Condon et al. 2004). This work confirms that carbon isotope discrimination $\left(\Delta^{13} \mathrm{C}\right)$ can be used as a surrogate for water use efficiency in crop selection. We are interested in investigating the potential to use $\Delta^{13} \mathrm{C}$ as a proxy for water use efficiency in rice, where genetic variation for this trait has been demonstrated in upland rice genotypes (Dingkuhn et al. 1991). In addition, because $\Delta^{13} \mathrm{C}$ is a polygenic trait, we aimed to use quantitative trait locus (QTL) analysis to dissect it genetically and subsequently to construct near-isogenic lines (NILs) for use in physiological studies. Our longterm objective is to enhance our understanding of this trait in relation to crop productivity under water-limited conditions. QTL analysis also lays the foundation for using linked molecular markers in a marker-assisted selection strategy in a plant breeding program.

The first QTLs associated with $\Delta^{13} \mathrm{C}$ were reported by Martin et al. (1989) in tomato and since that time QTLs for $\Delta^{13} \mathrm{C}$ have been identified in rice (Price et al. 2002) and several other plant species (Brendel et al. 2002; Casasoli et al. 2004; Diab et al. 2004; Ellis et al. 2002; Gleick 2003; Hausmann et al. 2005; Masle et al. 2005; Rebetzke et al. 2008; Saranga et al. 2004; Scalfi et al. 2004; Specht et al. 2001; Teulat et al. 2002; Thumma et al. 2001). Until now, all QTL studies conducted in rice involved segregating populations evaluated at different growth stages in field environments. However, the limited reproducibility of field experiments emphasizes the need to better understand and more rigorously control environmental variation that may interfere with the evaluation of carbon isotope discrimination. Differences in phenology and development among plants in segregating populations may also affect measurements of carbon isotope discrimination, as the assay for $\Delta^{13} \mathrm{C}$ presents an integrated assessment of all changes in $\mathrm{CO}_{2}$ diffusion and/ or assimilation during the growth of the sampled tissue.

In this study, we identified QTLs associated with changes in $\Delta^{13} \mathrm{C}$ in young rice seedlings evaluated in a controlled environment (Comstock et al. 2005). Two populations were used, a population of doubled haploid (DH) lines and a set of recombinant inbred (RI) lines, both derived from the cross IR64 $\times$ Azucena. Two different experiments, each with two replications per line, were conducted for each population. A total of 14 traits were evaluated so that the relationships among QTLs associated with $\Delta^{13} \mathrm{C}$ could be related to QTLs associated with other components of photosynthesis and plant growth.

\section{Results}

Comparison of the IR64 $\times$ Azucena genetic maps for two segregating populations

The genetic map for the DH population covered $1,836.2 \mathrm{cM}$ and consisted of 395 well-distributed simple sequence repeat (SSR) and restriction fragment length polymorphism (RFLP) markers mapped onto $91 \mathrm{DH}$ lines. The genetic map for the RI population covered 1,675.4 cM and consisted of 220 SSR markers mapped onto 165 RI lines (Ahmadi et al. 2005). The DH and the RI maps were aligned based on a common set of 135 SSR markers (Supplemental Fig. 1). The order, but not the distance between markers, was conserved between populations and is consistent with the marker order along the rice pseudomolecules (TIGR v.5, www.gramene.org).

Phenotypic trait variation across four different experiments

Table 1 summarizes the experimental conditions for the four experiments conducted over the course of this study (where the $\mathrm{DH}$ population was evaluated in experiment 1 (E1) and E2 and the RI population was evaluated in E3 and E4, as described in detail in "Materials and methods"). The distributions of $\Delta^{13} \mathrm{C}$ in the $\mathrm{DH}$ and $\mathrm{RI}$ populations are summarized in Fig. 1. $\Delta^{13} \mathrm{C}$ mean values increased from E1 to E4. There was no significant difference between IR64 and Azucena for $\Delta^{13} \mathrm{C}$ in any of the experiments, but transgressive variation was observed in both populations, providing the basis for QTL mapping.

Table 2 presents the range of variation for all 14 traits measured in the four experiments, together with the parental values. As can be seen for $\Delta^{13} \mathrm{C}$, the RI population 
Table 1 Experimental Conditions

\begin{tabular}{|c|c|c|c|c|c|c|c|c|c|c|c|}
\hline Experiment \# & Pop & Start date & $\begin{array}{l}\text { Daily mean } \\
\text { GH PAR } \\
\left(\mu \mathrm{mol} / \mathrm{m}^{2} / \mathrm{s}\right)\end{array}$ & $\begin{array}{l}\text { Daily max } \\
\text { GH PAR } \\
\left(\mu \mathrm{mol} / \mathrm{m}^{2} / \mathrm{s}\right)\end{array}$ & $\begin{array}{l}\text { Mean } \\
\text { day \%RH }\end{array}$ & $\begin{array}{l}\text { Mean } \\
\text { night \%RH }\end{array}$ & $\begin{array}{l}\text { Mean day } \\
\text { air temp } \\
\left({ }^{\circ} \mathrm{C}\right)\end{array}$ & $\begin{array}{l}\text { Mean night } \\
\text { air temp } \\
\left({ }^{\circ} \mathrm{C}\right)\end{array}$ & $\begin{array}{l}\text { Mean day } \\
{\left[\mathrm{CO}_{2}\right]}\end{array}$ & $\begin{array}{l}\text { Mean night } \\
{\left[\mathrm{CO}_{2}\right]}\end{array}$ & $\begin{array}{l}\delta^{13} \mathrm{C} \text { derived } \\
\text { from keeling } \\
\text { plot }\end{array}$ \\
\hline E1 & DH & 3 Jan 2003 & 1,168 & 1,319 & 41.5 & 45.5 & 30.0 & 25.4 & 383 & 384 & -9.26 \\
\hline E2 & DH & 5 Mar 2003 & 1,147 & 1,677 & 49.5 & 61.0 & 32.1 & 27.7 & 383 & 392 & -9.16 \\
\hline E3 & RIL & 4 Sep 2003 & 687 & 1,246 & 51.0 & 62.5 & 32.6 & 27.7 & 364 & 382 & -8.45 \\
\hline E4 & RIL & 31 Oct 2003 & 743 & 1,135 & 58.0 & 61.0 & 31.2 & 27.3 & 349 & 378 & -7.81 \\
\hline
\end{tabular}

had more individuals and a larger range of variation for all traits than did the DH population. Leaf length (LL), leaf width (LW), and tiller number (TN) were highest in E4, reflecting the late sampling date. Photosynthesis, stomatal conductance, and the ratio of plant to air $\mathrm{CO}_{2}$ concentration were also slightly higher in E4. Significant genotype by trial interactions was detected for all traits except leaf nitrogen content $(\% \mathrm{~N})$ for each population and justified considering each experiment individually. Although trait means differed among experiments, reflecting slight seasonal differences in the greenhouse environments and/or differences in sampling date, the aerial biomass of Azucena was consistently higher than that of IR64, and the leaves of Azucena were also longer and wider than the leaves of IR64. Leaf abscisic acid (lABA) concentration was higher
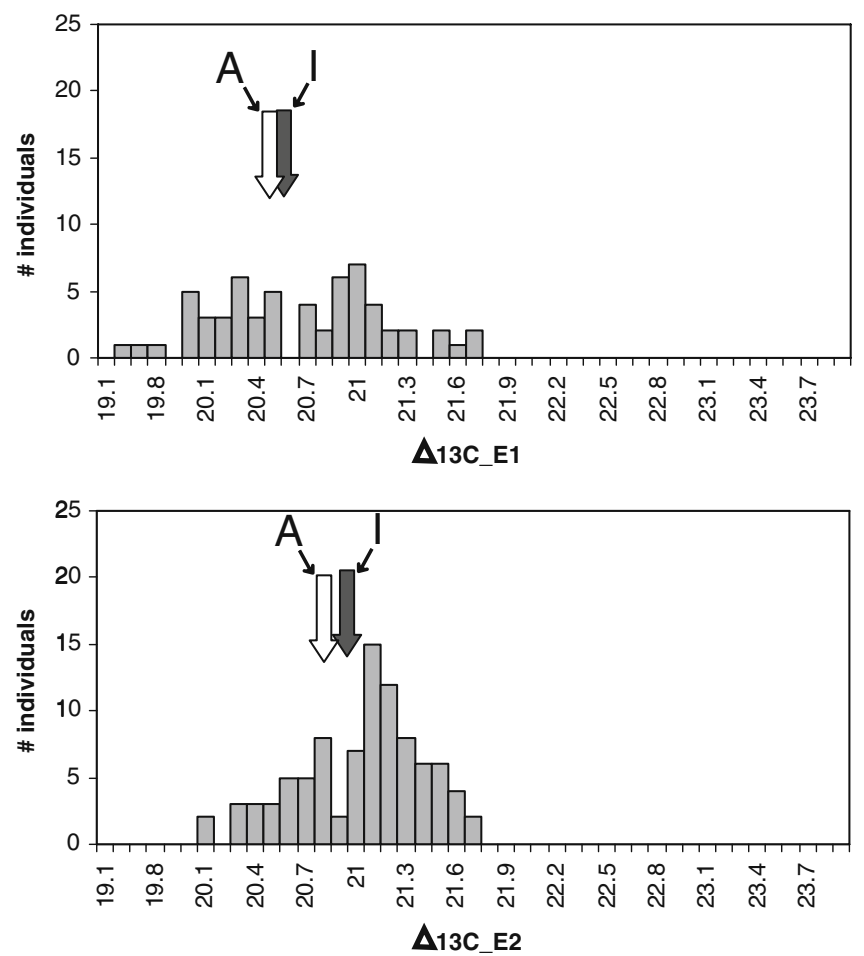

Fig. 1 Distribution of carbon isotope discrimination data $\left(\Delta^{13} \mathrm{C}\right.$; unit: per mill) for the IR64 $\times$ Azucena segregating populations in four experiments; E1 (60 DH individuals), E2 (91 DH individuals), E3 in IR64 compared to Azucena. Relative water content was measured in the RI population in E4 only, and this provided an opportunity to assess potential effects of water relations on the other traits evaluated in that experiment. Relative water content ranged from $73 \%$ to $93 \%$, indicating that some plants experienced a slight decrease in turgor. However, no significant genotype effect was detected for relative water content (RWC). Significant genotype effects were detected for all other traits measured, and broad sense heritabilities ranged between 0.50 and 0.94 (Table 2).

Phenotypic correlations between traits and experiments

Despite significant genotype by trial effects found for $\Delta^{13} \mathrm{C}$ in both populations, $\Delta^{13} \mathrm{C}$ values were significantly correlated

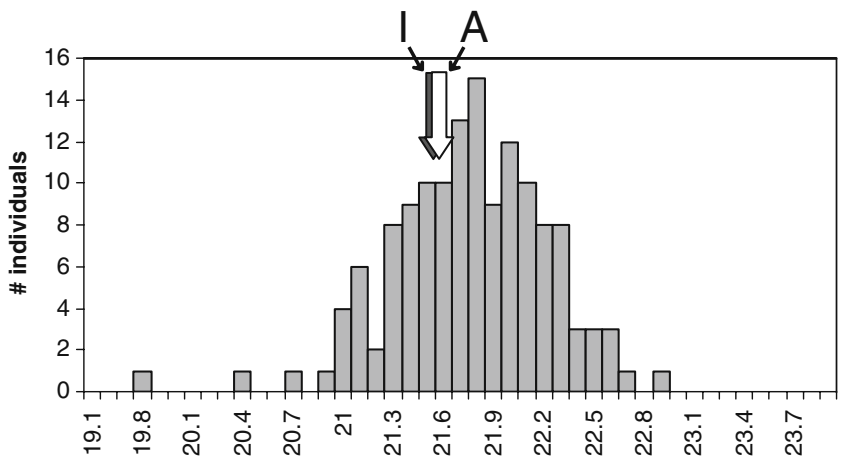

$\triangle 13 C_{-}$E3

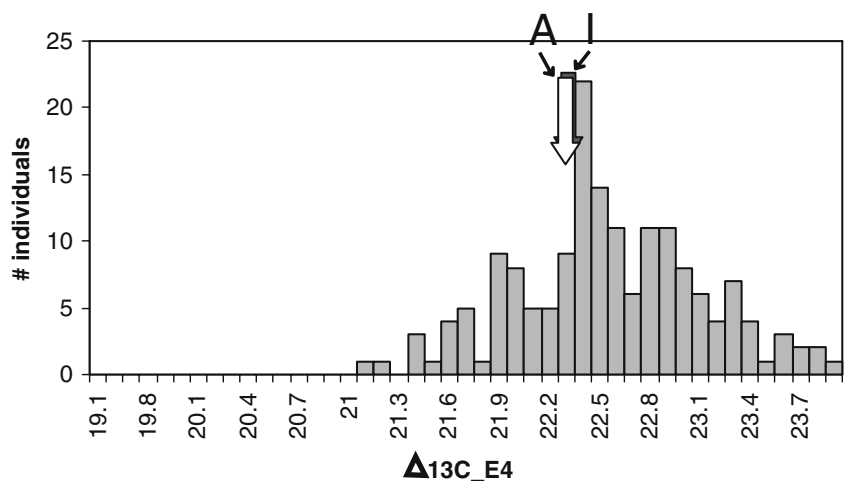

(139 RIL individuals), and E4 (165 RIL individuals). Arrows indicate parental values where $I=\operatorname{IR6} 64$ and $A=$ Azucena. 
Table 2 Trait Variation in the IR64 $\times$ Azucena Segregating Populations and the Parental Lines Across the Four Experiments

\begin{tabular}{|c|c|c|c|c|c|c|c|c|c|c|c|}
\hline Trait names (unit) & Exp & Pop & No. ind & Mean & SD & Min & $\operatorname{Max}$ & IR64 & Azucena & Trial CV & $h^{2}$ \\
\hline \multirow[t]{4}{*}{$\Delta 13 \mathrm{C}$ (per mil) } & E1 & DH & 62 & 20.64 & 0.52 & 19.56 & 21.69 & 20.56 & 20.51 & 1.6 & 0.81 \\
\hline & $\mathrm{E} 2$ & DH & 93 & 21.03 & 0.37 & 20.13 & 21.71 & 21.01 & 20.75 & 1.0 & 0.85 \\
\hline & E3 & RIL & 143 & 21.77 & 0.45 & 19.84 & 22.86 & 21.54 & 21.59 & 1.2 & 0.84 \\
\hline & E4 & RIL & 167 & 22.56 & 0.55 & 21.13 & 23.86 & 22.41 & 22.36 & 1.7 & 0.77 \\
\hline \multirow[t]{4}{*}{$\% \mathrm{~N}(\%)$} & E1 & DH & 62 & 5.11 & 0.25 & 4.52 & 5.66 & 4.89 & 5.25 & 3.9 & 0.69 \\
\hline & E2 & DH & 93 & 4.58 & 0.32 & 3.82 & 5.28 & 4.65 & 4.18 & 6.1 & 0.61 \\
\hline & E3 & RIL & 143 & 4.85 & 0.34 & 3.83 & 5.57 & 4.59 & 4.83 & 6.4 & 0.62 \\
\hline & E4 & RIL & 167 & 3.72 & 0.34 & 2.84 & 4.60 & 3.51 & 3.25 & 7.7 & 0.69 \\
\hline \multirow[t]{4}{*}{$\operatorname{SLA}\left(\mathrm{m}^{2} \mathrm{~kg}^{-1}\right)$} & E1 & DH & 62 & 23.42 & 2.27 & 18.80 & 28.07 & 25.19 & 21.37 & 6.0 & 0.80 \\
\hline & E2 & DH & 93 & 22.64 & 1.98 & 18.35 & 28.12 & 24.69 & 20.95 & 5.5 & 0.80 \\
\hline & E3 & RIL & 143 & 28.97 & 1.95 & 23.50 & 35.74 & 31.41 & 28.65 & 4.3 & 0.82 \\
\hline & E4 & RIL & 167 & 27.14 & 2.61 & 21.55 & 34.91 & 29.20 & 25.66 & 9.5 & 0.53 \\
\hline \multirow[t]{2}{*}{ SB (g) } & E1 & DH & 62 & 1.62 & 0.45 & 0.83 & 2.53 & 1.52 & 2.11 & 19.8 & 0.75 \\
\hline & E2 & DH & 93 & 2.41 & 0.42 & 1.45 & 3.13 & 2.68 & 3.10 & & \\
\hline \multirow[t]{3}{*}{ LW (mm) } & E2 & DH & 93 & 8.79 & 0.98 & 6.75 & 11.54 & 7.65 & 10.38 & 6.8 & 0.82 \\
\hline & E3 & RIL & 143 & 10.39 & 1.41 & 5.72 & 13.68 & 9.36 & 12.76 & 5.6 & 0.94 \\
\hline & E4 & RIL & 167 & 11.35 & 1.79 & 6.55 & 16.45 & 10.20 & 14.19 & 7.6 & 0.90 \\
\hline \multirow[t]{3}{*}{$\mathrm{LL}(\mathrm{cm})$} & E2 & DH & 93 & 53.00 & 5.20 & 39.10 & 66.51 & 50.04 & 58.83 & 4.9 & 0.88 \\
\hline & E3 & RIL & 143 & 62.05 & 7.34 & 41.44 & 83.29 & 56.25 & 75.05 & 5.3 & 0.93 \\
\hline & E4 & RIL & 167 & 75.03 & 9.03 & 55.05 & 102.22 & 70.23 & 90.98 & 5.4 & 0.91 \\
\hline \multirow[t]{3}{*}{ TN (\#) } & E2 & DH & 93 & 12.48 & 2.43 & 6.71 & 19.00 & 15.79 & 11.06 & 13.3 & 0.77 \\
\hline & E3 & RIL & 143 & 9.49 & 2.27 & 4.17 & 17.02 & 14.56 & 7.40 & 19.2 & 0.80 \\
\hline & E4 & RIL & 167 & 13.43 & 3.82 & 4.71 & 27.48 & 22.06 & 10.13 & 17.4 & 0.85 \\
\hline LF (score 1-3) & E2 & DH & 93 & 1.66 & 0.62 & 1.00 & 3.00 & 1.00 & 1.50 & 21.3 & 0.84 \\
\hline (score 1-5) & E4 & RIL & 167 & 2.11 & 0.80 & 1.00 & 4.56 & 1.64 & 2.14 & 20.5 & 0.86 \\
\hline LE (score $1-3$ ) & E2 & DH & 93 & 1.66 & 0.61 & 1.00 & 3.00 & 2.00 & 3.00 & 15.4 & 0.84 \\
\hline (score 1-5) & E4 & RIL & 167 & 2.17 & 0.63 & 1.00 & 3.93 & 1.64 & 2.14 & 19.3 & 0.78 \\
\hline \multirow[t]{2}{*}{$\mathrm{Ci} / \mathrm{Ca}\left(\mu 1^{-1}\right)$} & E3 & RIL & 140 & 276.15 & - & 242.00 & 299.36 & 272.77 & 285.77 & - & - \\
\hline & E4 & RIL & 166 & 287.64 & 9.18 & 257.01 & 304.02 & 280.05 & 290.93 & 2.9 & 0.57 \\
\hline \multirow[t]{2}{*}{$\mathrm{A} / \mathrm{m} 2\left(\mu \mathrm{mol} \mathrm{m}^{-2} \mathrm{~s}^{-1}\right)$} & E3 & RIL & 140 & 26.19 & - & 19.00 & 35.89 & 25.37 & 26.62 & - & - \\
\hline & E4 & RIL & 167 & 27.00 & 2.67 & 20.87 & 33.39 & 25.59 & 24.49 & 7.6 & 0.71 \\
\hline \multirow[t]{2}{*}{$\mathrm{SCO}\left(\mathrm{mol} \mathrm{m} \mathrm{m}^{-2} \mathrm{~s}^{-1}\right)$} & E3 & RIL & 140 & 0.50 & - & 0.29 & 0.85 & 0.46 & 0.56 & - & - \\
\hline & E4 & RIL & 167 & 0.60 & 0.10 & 0.33 & 0.86 & 0.51 & 0.56 & 14.1 & 0.69 \\
\hline RWC (\%) & E4 & RIL & 167 & 0.87 & 0.03 & 0.73 & 0.93 & 0.85 & 0.90 & 4.6 & - \\
\hline \multirow[t]{2}{*}{ 1ABA $\left(\ln \left(\mathrm{nmol} \mathrm{m}^{-2}\right)\right)$} & E3 & RIL & 143 & 1.72 & 0.35 & 0.31 & 2.70 & 2.13 & 1.30 & 19.6 & 0.67 \\
\hline & E4 & RIL & 167 & 0.58 & 0.38 & -0.64 & 2.14 & 0.05 & 0.07 & 67.8 & 0.50 \\
\hline
\end{tabular}

between experiments in both populations $(r=0.6, P<0.0001$ in both cases). $\Delta^{13} \mathrm{C}$ was negatively correlated with leaf width and leaf length ( $r=-0.3$ in E2, $r=-0.4$ in E4), while leaf length was positively correlated with leaf width in both populations $(r=0.4$ in $\mathrm{E} 2$, in $\mathrm{E} 3$, and in $\mathrm{E} 4) . \Delta^{13} \mathrm{C}$ was positively correlated with leaf blade flatness (LF; $r=0.4$ in $\mathrm{E} 2$ and $r=0.2$ in E4). In the RI population, $\Delta{ }^{13} \mathrm{C}$ was negatively correlated with ABA concentration $(r=-0.3$ in $\mathrm{E} 4)$, and it was positively correlated with $\mathrm{A}, \mathrm{C}_{\mathrm{i}} / \mathrm{C}_{\mathrm{a}}$, and stomatal conductance (SCO; $\mathrm{E} 3$ and $\mathrm{E} 4, r=0.3$ to 0.4 ), while A was positively correlated with $\mathrm{C}_{\mathrm{i}} / \mathrm{C}_{\mathrm{a}}$ and $\mathrm{SCO}$ in both experiments (E3 and $\mathrm{E} 4, r=0.3$ to 0.8 ). Leaf length was negatively correlated with $\% \mathrm{~N}$ in E2 $(r=-0.3)$, E3 $(r=-0.4)$, and E4 $(r=-0.5)$. Leaf flatness and leaf erectness (LE) were strongly and negatively correlated in E2 and E4 $(r=-0.6)$. Complete data for all traits and experiments can be found in Supplemental Table 1.

QTL identification

A summary of QTL results is presented in Table 3. QTL names include a trait abbreviation (as summarized in 
Table 3 Results of QTL Analysis for 14 Traits Identified in the Four Experiments for the IR64 × Azucena Populations

\begin{tabular}{|c|c|c|c|c|c|c|c|c|c|c|}
\hline QTL $^{\mathrm{a}}$ & $\mathrm{Chr}$ & $\begin{array}{l}\text { Marker interval } \\
\text { flanking peak }\end{array}$ & $\begin{array}{l}\text { Position cM } \\
\text { (confidence interval) }\end{array}$ & Pop & $\begin{array}{l}\text { QTL } \\
\text { cluster }^{\mathrm{c}}\end{array}$ & $\begin{array}{l}\text { LOD score } \\
\text { threshold }^{\mathrm{d}}\end{array}$ & $\begin{array}{l}\text { LOD } \\
\text { score }\end{array}$ & $R^{2 \mathrm{e}}$ & $a^{\mathrm{f}}$ & ANOVA \\
\hline$\Delta^{13} \mathrm{C} 4.1 \_\mathrm{E} 2$ & 4 & RM280-RM567 & $131.2(122.3-134.7)$ & DH & $4-\mathrm{C}$ & 3.25 & 4.21 & 0.13 & -0.138 & $\_\mathrm{g}$ \\
\hline$\Delta^{13} \mathrm{C} 4.1 \_\mathrm{E} 3$ & 4 & RM518-RM261 & $17.7(11.7-29.2)$ & RIL & $4-A$ & 3.11 & 3.08 & 0.08 & 0.137 & $-{ }^{\mathrm{h}}$ \\
\hline$\Delta^{13} \mathrm{C}$ 4.1_E4 & 4 & RM307-RM185 & $27.2(24.1-31.2)$ & RIL & $4-A$ & 3.17 & 5.23 & 0.11 & 0.193 & $-^{\mathrm{i}}$ \\
\hline$\Delta^{13} \mathrm{C} 4.2 \_\mathrm{E} 3$ & 4 & RM252-RM241 & $89.1(85.9-93.1)$ & RIL & $4-B$ & 3.11 & 3.73 & 0.08 & -0.140 & j \\
\hline$\Delta^{13} \mathrm{C} 4.2 \_\mathrm{E} 4$ & 4 & RM317-RM349 & $124.5(118.5-127.7)$ & RIL & $4-\mathrm{C}$ & 3.17 & 4.51 & 0.11 & -0.190 & $\_\mathrm{g}$ \\
\hline$\Delta^{13} C 5.1 \_E 1$ & 5 & $R Z 67$ & 108.3 & $D H$ & $5-\mathrm{A}$ & 3.30 & 1.89 & 0.10 & 0.175 & $-{ }^{\mathrm{i}}$ \\
\hline$\Delta^{13} \mathrm{C}$ 5.1_E2 & 5 & RM459-RM161 & $87.8(81.9-92.9)$ & DH & $5-\mathrm{A}$ & 3.25 & 5.71 & 0.19 & 0.165 & $\_\mathrm{g}$ \\
\hline$\Delta^{13} \mathrm{C}$ 5.1_E3 & 5 & RM440-RM188 & $113.3(103.0-119.3)$ & RIL & $5-\mathrm{A}$ & 3.11 & 5.76 & 0.15 & 0.186 & $-{ }^{\mathrm{i}}$ \\
\hline$\Delta^{13} \mathrm{C}$ 5.1_E4 & 5 & RM440-RM188 & $107.0(101.0-119.3)$ & RIL & $5-\mathrm{A}$ & 3.17 & 5.07 & 0.13 & 0.202 & $\_\mathrm{g}$ \\
\hline$\Delta^{13} \mathrm{C} 8.1 \_\mathrm{E} 1$ & 8 & RM547-RM72 & $54.4(49.7-58.4)$ & DH & 8-A & 3.3 & 3.38 & 0.15 & 0.207 & $-{ }^{\mathrm{i}}$ \\
\hline$\Delta^{13} C 8.1 \_E 4$ & 8 & $R M 342 b$ & 77.24 & $R I L$ & 8-A & 3.17 & 3.05 & 0.06 & 0.138 & $\_\mathrm{g}$ \\
\hline \%N1.1_E3 & 1 & RM431-RM165 & $209.8(204.1-213.8)$ & RIL & $1-\mathrm{C}$ & 3.11 & 7.09 & 0.20 & -0.157 & $-{ }^{\mathrm{i}}$ \\
\hline$\% \mathrm{~N} 1.1 \_\mathrm{E} 4$ & 1 & RM165-RM14 & $224.0(209.8-230.0)$ & RIL & $1-\mathrm{C}$ & 3.19 & 3.26 & 0.09 & -0.105 & ${ }^{\mathrm{j}}$ \\
\hline \%N2.1_E1 & 2 & RM492-RM452 & $62.8(60.5-68.5)$ & DH & $2-\mathrm{B}$ & 3.42 & 3.74 & 0.19 & 0.117 & $\_\mathrm{g}$ \\
\hline$\% \mathrm{~N} 2.1 \_\mathrm{E} 2$ & 2 & RG437-RM492 & $61.5(60.5-71.3)$ & DH & $2-\mathrm{B}$ & 3.11 & 4.90 & 0.15 & 0.129 & $\_\mathrm{g}$ \\
\hline$\%$ N5.1_E3 & 5 & RM440-RM188 & $105.0(101.0-117.3)$ & RIL & $5-\mathrm{A}$ & 3.11 & 5.65 & 0.18 & 0.147 & $-{ }^{\mathrm{i}}$ \\
\hline \%N10.1_E2 & 10 & RG257-RM467 & $35.7(29.7-47.0)$ & DH & $10-\mathrm{A}$ & 3.11 & 3.96 & 0.13 & 0.114 & \lrcorner$^{j}$ \\
\hline \%N11.1_E2 & 11 & RM116-RM441 & $43.0(40.0-49.0)$ & DH & $11-\mathrm{A}$ & 3.11 & 3.59 & 0.11 & 0.102 & $\_\mathrm{g}$ \\
\hline SLA1.1_E3 & 1 & RM431-RM165 & $207.8(204.1-213.8)$ & RIL & 1-C & 3.17 & 3.19 & 0.06 & -0.510 & $-\mathrm{j}$ \\
\hline SLA4.1_E4 & 4 & RM518-RM261 & $17.2(13.7-25.2)$ & RIL & $4-\mathrm{A}$ & 3.21 & 5.30 & 0.15 & -1.046 & $\_\mathrm{g}$ \\
\hline SLA5.1_E1 & 5 & RM459-RM161 & 86.5 (81.9-89.8) & DH & $5-\mathrm{A}$ & 3.42 & 5.27 & 0.19 & -1.008 & ${ }^{\mathrm{j}}$ \\
\hline SLA5.1_E2 & 5 & RM459-RM161 & 87.8 (81.9-89.8) & DH & $5-\mathrm{A}$ & 3.30 & 6.30 & 0.23 & -0.963 & $-{ }^{\mathrm{i}}$ \\
\hline SLA5.1_E3 & 5 & RM440-RM188 & $97.0(94.2-101.0)$ & RIL & $5-\mathrm{A}$ & 3.17 & 7.15 & 0.16 & -0.800 & $-{ }^{\mathrm{i}}$ \\
\hline SLA9.1_E3 & 9 & RM257-RM242 & $62.0(60.4-64.0)$ & RIL & $9-\mathrm{A}$ & 3.17 & 6.07 & 0.13 & 0.730 & $\_\mathrm{g}$ \\
\hline SLA12.1_E3 & 12 & RM309-RM7018 & $71.9(69.5-81.8)$ & RIL & $12-\mathrm{A}$ & 3.17 & 3.59 & 0.07 & -0.530 & $-{ }^{\mathrm{h}}$ \\
\hline SB1.1_E1 & 1 & RG331-RM568 & $206.1(205.6-206.1)$ & DH & 1-C & 3.45 & 6.45 & 0.29 & 0.249 & $-^{\mathrm{i}}$ \\
\hline SB1.1_E2 & 1 & RG331-RM568 & $206.1(205.6-206.1)$ & $\mathrm{DH}$ & $1-\mathrm{C}$ & 3.33 & 7.33 & 0.22 & 0.194 & $-^{\mathrm{i}}$ \\
\hline SB11.1_E2 & 11 & RM167-RG118 & $34.1(31.6-38.4)$ & DH & $11-\mathrm{A}$ & 3.33 & 4.30 & 0.13 & -0.159 & ${ }_{-}^{j}$ \\
\hline SB12.1_E2 & 12 & RG901-RM270 & $90.5(84.7-98.2)$ & DH & $12-\mathrm{B}$ & 3.33 & 4.50 & 0.12 & 0.147 & ${ }^{\mathrm{j}}$ \\
\hline LW2.1_E3 & 2 & RM475-RM5430 & $79.2(73.9-83.6)$ & RIL & $2-\mathrm{D}$ & 3.05 & 3.80 & 0.08 & 0.403 & $\_\mathrm{g}$ \\
\hline LW2.1_E4 & 2 & RM452-RM324 & $39.0(32.7-43.0)$ & RIL & $2-\mathrm{B}$ & 3.05 & 3.40 & 0.06 & 0.435 & \\
\hline LW4.1_E2 & 4 & RG214-RG143 & $118.3(112.3-122.3)$ & DH & $4-\mathrm{C}$ & 3.38 & 7.30 & 0.21 & 0.454 & $\_\mathrm{g}$ \\
\hline LW4.1_E3 & 4 & RM307-RM185 & $25.2(24.1-27.2)$ & RIL & $4-\mathrm{A}$ & 3.02 & 7.77 & 0.18 & -0.607 & $-{ }^{\mathrm{i}}$ \\
\hline LW4.1_E4 & 4 & RM307-RM185 & $25.2(24.1-27.1)$ & RIL & $4-\mathrm{A}$ & 3.05 & 15.91 & 0.31 & -1.014 & $-{ }^{\mathrm{i}}$ \\
\hline LW4.2_E4 & 4 & RM317-RM349 & $122.5(118.5-127.8)$ & RIL & $4-\mathrm{C}$ & 3.05 & 5.32 & 0.12 & 0.624 & ${ }^{\mathrm{j}}$ \\
\hline LW5.1_E4 & 5 & RM163-RM440 & $92.2(88.2-107.0)$ & RIL & $5-\mathrm{A}$ & 3.05 & 3.46 & 0.07 & -0.469 & $-{ }^{\mathrm{h}}$ \\
\hline LW12.1_E2 & 12 & RM17-RG181 & $110.5(92.2-112.5)$ & DH & $12-\mathrm{B}$ & 3.38 & 4.52 & 0.12 & 0.348 & $\_\mathrm{g}$ \\
\hline LL1.1_E3 & 1 & RM472-RM431 & $204.1(199.8-213.8)$ & RIL & $1-\mathrm{C}$ & 3.17 & 3.20 & 0.08 & 1.082 & ${ }_{-}^{j}$ \\
\hline LL1.1_E4 & 1 & RM472-RM431 & $206.1(202.1-211.8)$ & RIL & $1-\mathrm{C}$ & 3.05 & 5.81 & 0.13 & 3.311 & $\_\mathrm{g}$ \\
\hline LL2.1_E2 & 2 & RM497-RM6 & $163.3(159.3-168.4)$ & DH & $2-\mathrm{E}$ & 3.15 & 6.74 & 0.17 & -1.578 & $\_\mathrm{g}$ \\
\hline LL2.1_E4 & 2 & RM250-RM166 & $125.7(115.1-129.4)$ & RIL & $2-\mathrm{E}$ & 3.05 & 3.45 & 0.07 & -2.430 & ${ }_{-}^{j}$ \\
\hline LL3.1_E2 & 3 & RM514-RM570 & $236.0(228.3-244.4)$ & DH & $3-\mathrm{C}$ & 3.15 & 3.96 & 0.10 & 1.218 & $\_\mathrm{g}$ \\
\hline LL3.1_E3 & 3 & RM143-RM514 & $200.5(190.5-203.2)$ & RIL & $3-\mathrm{C}$ & 3.17 & 3.56 & 0.09 & 2.320 & $-^{\mathrm{i}}$ \\
\hline LL3.1_E4 & 3 & RM143-RM514 & $194.5(186.5-200.5)$ & RIL & $3-\mathrm{C}$ & 3.05 & 5.64 & 0.14 & 3.391 & $--^{\mathrm{i}}$ \\
\hline LL12.1_E3 & 12 & RM6123-RM17 & $114.0(106.0-114.0)$ & RIL & $12-\mathrm{B}$ & 3.17 & 5.27 & 0.13 & 2.586 & $\_\mathrm{g}$ \\
\hline LL12.1_E4 & 12 & RM6123-RM17 & $110.0(104.0-114.0)$ & RIL & $12-\mathrm{B}$ & 3.05 & 4.41 & 0.11 & 2.999 & $-^{\mathrm{g}}$ \\
\hline TN1.1_E2 & 1 & RM472-RM431 & $190.9(187.3-198.9)$ & DH & $1-\mathrm{C}$ & 3.23 & 5.13 & 0.17 & 1.082 & ${ }^{\mathrm{j}}$ \\
\hline TN2.1_E3 & 2 & RM263-RM526 & $91.7(83.7-94.0)$ & RIL & $2-\mathrm{D}$ & 3.22 & 3.45 & 0.08 & -0.663 & $\_\mathrm{g}$ \\
\hline
\end{tabular}


Table 3 (continued)

\begin{tabular}{|c|c|c|c|c|c|c|c|c|c|c|}
\hline $\mathrm{QTL}^{\mathrm{a}}$ & Chr & $\begin{array}{l}\text { Marker interval } \\
\text { flanking peak }\end{array}$ & $\begin{array}{l}\text { Position cM } \\
\text { (confidence interval) }\end{array}$ & Pop & $\begin{array}{l}\text { QTL } \\
\text { cluster }^{\mathrm{c}}\end{array}$ & $\begin{array}{l}\text { LOD score } \\
\text { threshold }^{\mathrm{d}}\end{array}$ & $\begin{array}{l}\text { LOD } \\
\text { score }\end{array}$ & $R^{2 \mathrm{e}}$ & $a^{\mathrm{f}}$ & ANOVA \\
\hline TN2.1_E4 & 2 & RM550-RM465C & $45.6(39.0-47.6)$ & RIL & $2-\mathrm{B}$ & 3.11 & 4.87 & 0.09 & -1.177 & $-{ }^{\mathrm{i}}$ \\
\hline TN2.2_E4 & 2 & RM5651-RM106 & $81.6(79.1-85.6)$ & RIL & 2-D & 3.11 & 4.11 & 0.08 & -1.086 & $-{ }^{\mathrm{i}}$ \\
\hline TN8.1_E3 & 8 & RM433-RM281 & $128.9(124.9-132.9)$ & RIL & $8-\mathrm{B}$ & 3.22 & 6.53 & 0.17 & -1.000 & $-{ }^{\mathrm{i}}$ \\
\hline TN8.1_E4 & 8 & RM433-RM281 & $130.9(126.9-132.9)$ & RIL & $8-\mathrm{B}$ & 3.11 & 5.93 & 0.14 & -1.507 & $-{ }^{\mathrm{i}}$ \\
\hline LF1.1_E2 & 1 & RM543-RM302 & $153.0(146.8-155.0)$ & DH & $1-\mathrm{B}$ & 3.29 & 4.42 & 0.12 & 0.223 & $-{ }^{\mathrm{h}}$ \\
\hline LF1.1_E4 & 1 & RM200-RM319 & $177.1(173.1-180.8)$ & RIL & $1-\mathrm{B}$ & 3.08 & 4.33 & 0.07 & 0.226 & $--^{\mathrm{i}}$ \\
\hline LF2.1_E4 & 2 & RM561-RM341 & $57.1(51.3-63.9)$ & RIL & $2-\mathrm{C}$ & 3.08 & 3.59 & 0.06 & 0.200 & $-{ }^{\mathrm{i}}$ \\
\hline LF3.1_E2 & 3 & RM156-RM411 & $134.6(128.4-136.6)$ & DH & $3-\mathrm{A}$ & 3.29 & 5.56 & 0.13 & -0.233 & $-{ }^{\mathrm{i}}$ \\
\hline LF5.1_E2 & 5 & CDO105-RZ649 & $78.9(76.9-89.8)$ & DH & $5-\mathrm{A}$ & 3.29 & 8.03 & 0.28 & 0.335 & $-{ }^{\mathrm{i}}$ \\
\hline LF5.1_E4 & 5 & RM163-RM440 & $101.0(97.0-107.0)$ & RIL & $5-\mathrm{A}$ & 3.08 & 9.55 & 0.22 & 0.388 & $-{ }^{\mathrm{i}}$ \\
\hline LF11.1_E4 & 11 & RM332-RM167 & $14.0(9.8-18.0)$ & RIL & $11-\mathrm{A}$ & 3.08 & 3.49 & 0.06 & 0.196 & $-{ }^{\mathrm{i}}$ \\
\hline LE3.1_E2 & 3 & RM168-RM520 & $190.7(179.2-202.8)$ & DH & 3-B & 3.22 & 4.28 & 0.17 & 0.231 & ${ }^{\mathrm{j}}$ \\
\hline LE4.1_E4 & 4 & RM518-RM261 & $17.7(13.7-27.2)$ & RIL & $4-\mathrm{A}$ & 3.20 & 3.84 & 0.10 & 0.201 & ${ }^{\mathrm{j}}$ \\
\hline LE5.1_E4 & 5 & RM440-RM188 & $111.2(105.0-119.3)$ & RIL & $5-\mathrm{A}$ & 3.20 & 3.87 & 0.08 & -0.178 & $\_\mathrm{g}$ \\
\hline LE6.1_E2 & 6 & RM528-RM30 & $129.9(129.2-139.6)$ & DH & $6-\mathrm{A}$ & 3.22 & 5.32 & 0.16 & -0.227 & $\_\mathrm{g}$ \\
\hline LE6.1_E4 & 6 & RM275-RM30 & $86.5(80.5-102.5)$ & RIL & $6-\mathrm{A}$ & 3.20 & 3.59 & 0.09 & -0.193 & j \\
\hline A/m24.1_E3 & 4 & RM518-RM261 & $19.7(13.7-24.1)$ & RIL & $4-\mathrm{A}$ & 3.17 & 4.37 & 0.14 & 1.019 & $-{ }^{\mathrm{i}}$ \\
\hline A/m24.1_E4 & 4 & RM518-RM261 & $19.7(17.7-24.1)$ & RIL & $4-\mathrm{A}$ & 3.09 & 8.17 & 0.16 & 1.290 & $-{ }^{\mathrm{i}}$ \\
\hline Ci/Ca1.1_E4 & 1 & RM265-RM315 & $184.6(180.3-190.6)$ & RIL & $1-\mathrm{C}$ & 3.15 & 3.28 & 0.07 & 2.536 & $\_\mathrm{g}$ \\
\hline$C i / C a 2.1 \_E 3^{\mathrm{f}}$ & 2 & $R M 423$ & 16.2 & $R I L$ & $2-A$ & 3.20 & 2.77 & 0.08 & -3.077 & j \\
\hline $\mathrm{Ci} / \mathrm{Ca} 2.1 \_\mathrm{E} 4$ & 2 & RM423-RM555 & $18.3(11.3-22.7)$ & RIL & $2-\mathrm{A}$ & 3.15 & 3.47 & 0.08 & -2.704 & $\_\mathrm{g}$ \\
\hline$C i / C a 4.1 \_E 4^{\mathrm{f}}$ & 4 & RM518 & 15.7 & $R I L$ & $4-\mathrm{A}$ & 3.15 & 2.69 & 0.08 & 2.600 & $j^{j}$ \\
\hline SCO1.1_E4 & 1 & RM034-RM246 & $133.5(129.5-140.5)$ & RIL & $1-\mathrm{A}$ & 3.03 & 4.47 & 0.13 & 0.039 & $\_\mathrm{g}$ \\
\hline SCO4.1_E4 & 4 & RM518-RM261 & $17.7(15.7-27.2)$ & RIL & $4-\mathrm{A}$ & 3.03 & 8.32 & 0.19 & 0.048 & $-{ }^{\mathrm{i}}$ \\
\hline 1ABA4.1_E4 & 4 & RM307-RM185 & $25.2(24.1-29.2)$ & RIL & $4-\mathrm{A}$ & 3.02 & 3.11 & 0.07 & -0.070 & j \\
\hline 1ABA12.1_E3 & 12 & RM270-RM235 & $100.4(94.4-108.0)$ & RIL & $12-\mathrm{B}$ & 3.02 & 4.09 & 0.13 & 0.130 & j \\
\hline
\end{tabular}

Loci indicated in italics represent potential QTL detected only by single marker analysis

DH doubled haploid population, RIL recombinant inbred lines

a QTL nomenclature is as described in "Results" section, "QTL identification"

${ }^{\mathrm{b}}$ Marker interval indicates the interval in which the QTL peak is found. Confidence interval = peak LOD scores minus 1

${ }^{\mathrm{c}}$ QTL cluster indicates chromosomal regions shared by several QTLs based on marker comparison between the two populations used in this study

${ }^{\mathrm{d}}$ LOD score threshold has been calculated with 1,000 permutations

${ }^{\mathrm{e}} R^{2}$ : variance explained by the QTL

${ }^{\mathrm{f}}$ Additive effect (increasing allele effect) provided by Azucena

${ }^{\mathrm{g}}$ Significance at the $0.1 \%$ level by single marker analysis

${ }^{\mathrm{h}}$ Significance at the $5 \%$ by single marker analysis

${ }^{\mathrm{i}}$ Significance at the $0.01 \%$ level by single marker analysis

${ }^{\mathrm{j}}$ Significance at the $1 \%$ level by single marker analysis

Table 2) followed by the chromosome on which the QTL is located, a period (“."), a unique numerical identifier, followed by an understroke ("_"), and the number of the experiment in which the QTL was identified. Each trait $\times$ experiment combination was evaluated independently, and QTL nomenclature reflects that fact. Many QTLs for the same trait mapped to the same location (referred to as a cluster) across experiments, but they are presented as independent bits of information in Table 3; the colocalization of independently measured QTLs offers support for the existence of a QTL effect in a given location. Most traits were measured in both populations, with the exception that total aerial shoot biomass (SB) was measured only in the $\mathrm{DH}$ population (E1 and E2), and leaf photosynthesis (A/ $\mathrm{m} 2$ ), the ratio of intercellular to ambient $\mathrm{CO}_{2}$ concentration $\left(\mathrm{C}_{\mathrm{i}} / \mathrm{C}_{\mathrm{a}}\right), \mathrm{SCO}$, and $\mathrm{ABBA}$ concentration were measured only 
on the RI population (E3 and E4). A description of salient QTLs associated with each trait and each experiment is outlined below and a summary of all QTLs identified in this study can be found in Supplemental Fig. 1.

Carbon isotope discrimination $\left(\Delta^{13} C\right)$ A total of 11 QTLs clustering in five chromosomal regions and explaining 8 $19 \%$ of the phenotypic variation was identified for $\Delta^{13} \mathrm{C}$. The QTLs with the largest effect on $\Delta{ }^{13} \mathrm{C}$ from both populations were colocated on chromosome 5 (Fig. 2). They explained between $13 \%$ and $19 \%$ of the phenotypic variation (Table 3), and the IR64 allele was associated with lower $\Delta^{13} \mathrm{C}$. The IR64 allele had a similar effect at two $\Delta^{13} \mathrm{C}$ QTLs clustered near the centromere on chromosome 4 in the RI population $\left(R^{2}=0.08\right.$ and 0.11$)$ and at one on chromosome 8 in the DH population $\left(R^{2}=\right.$ 0.15). In contrast, Azucena alleles were responsible for lower $\Delta^{13} \mathrm{C}$ at QTLs on the long arm of chromosome 4 in both populations.

Leaf nitrogen $(\% N)$ Seven QTLs were associated with percent nitrogen in the leaf, analyzed using the same ground leaf samples as were used for detecting $\Delta \Delta^{13} \mathrm{C}$. There was a strong support for a QTL on chromosome 1 detected in the recombinant inbred lines (RIL) population, with \% N1.1_E3 having the largest $R^{2}$ value $\left(R^{2}=0.20\right)$ of any $\% \mathrm{~N}$ QTL. Enhanced nitrogen content was associated with the IR64 allele at this locus, in contrast to the QTLs on other chromosomes where an increase in $\% \mathrm{~N}$ was associated with Azucena alleles. The QTL on chromosome 5 (\%N5.1_E3, $\left.R^{2}=0.18\right)$ was colocated with QTLs for $\Delta^{13} \mathrm{C}$.

Specific leaf area Variation for specific leaf area was associated with seven QTLs that clustered into five chromosomal regions. On chromosome 5, overlapping QTLs from both populations were identified in E1, E2, and E3 (Fig. 2). This QTL interval included QTLs for both $\Delta^{13} \mathrm{C}$ and $\% \mathrm{~N}$, as described above. The IR64 allele was associated with greater specific leaf area (SLA) and lower $\Delta^{13} \mathrm{C}$ at this locus but associated with lower $\% \mathrm{~N}$ too. SLA.1_E4 also colocated with a QTL for $\Delta^{13} \mathrm{C}$. Additional QTLs for SLA were identified on chromosomes 1, 9, and 12. For those on chromosomes 1 and 12, the IR64 allele increased SLA, while for the QTL on chromosome 9, the Azucena allele increased SLA. None of these QTLs were in intervals shared by QTLs for $\Delta^{13} \mathrm{C}$ or $\% \mathrm{~N}$.

Total aerial shoot biomass SB was measured only in the DH population (E1 and E2). A major QTL was identified on chromosome 1, near the telomere of the long arm in both experiments. At both SB1.1 E1 and SB1.1 E2, the Azucena allele increased SB. Additional QTLs were identified on chromosome 11 and on chromosome 12.
Leaf width Eight QTLs were associated with leaf width, and they clustered in six locations on chromosomes 2, 4, 5, and 12 (Table 3). The two clusters on chromosome 4 and the cluster on chromosome 5 corresponded to QTL intervals containing $\Delta^{13} \mathrm{C}$ QTLs (Fig. 2). At these loci, wider leaves were associated with lower $\Delta{ }^{13} \mathrm{C}$, regardless of which parental line contributed the wide-leaf allele.

Leaf length Nine QTLs clustering in four chromosomal locations were identified for LL with Azucena alleles contributing to increased leaf length at seven of them. None of them colocalized with QTLs for $\Delta^{13} \mathrm{C}$ or $\% \mathrm{~N}$, but LL1.1_E3 and LL1.1_E4 colocated with a QTL region for $\% \mathrm{~N}$. On chromosome 12, LL QTLs were located along with QTLs for SB and LW, with Azucena alleles contributing positively to all three traits.

Tiller number Five QTLs, clustered in four chromosomal locations, were associated with TN in the RI population, and one, nonoverlapping, TN QTL was identified in the DH population. In all cases except TN1.1_E2, positive alleles were provided by IR64. A pair of overlapping QTLs on chromosome 8, TN8.1_E3 $\left(R^{2}=0.17\right)$ and TN8.1_E4 $\left(R^{2}=\right.$ $0.14)$, explains the largest proportion of phenotypic variation for $\mathrm{TN}$ but does not overlap with any other trait.

Leaf blade flatness The most significant QTLs for LF were identified in the same location on chromosome 5 in both populations. $L F 5.1 \_E 2\left(R^{2}=0.28\right)$ and LF5.1_E4 $\left(R^{2}=0.22\right)$ were located in the same interval as QTLs for $\Delta{ }^{13} \mathrm{C}, \% \mathrm{~N}$, SLA, LW, and leaf erectness. The Azucena allele was associated with increased leaf blade flatness at this locus in both populations. Other QTLs for LF were identified on chromosomes 1, 2, 3, and 11 .

Leaf erectness A total of five QTLs were identified for LE on chromosomes 3, 4, 5, and 6, and only LE6.1_E2 and LE6.1_E4 presented the same QTL intervals in both populations. LE4.1_E4 was associated with an increased effect from Azucena allele and was in the same interval as a QTL for $\Delta^{13} \mathrm{C}, \mathrm{SLA}, \mathrm{LW}, \mathrm{A} / \mathrm{m} 2, \mathrm{Ci} / \mathrm{Ca}, \mathrm{SCO}$, and $1 \mathrm{ABA}$. LE5.1_E4 was also in an interval that overlapped with QTLs for $\Delta^{13} \mathrm{C}$, SLA, and LW, but the positive effect on LE at this locus was associated with the IR64 allele.

Photosynthetic gas exchange The RI population was analyzed with leaf gas exchange techniques for photosynthetic $\mathrm{CO}_{2}$ assimilation rate $\left(\mathrm{A} / \mathrm{m}^{2}\right)$, the ratio of intercellular to ambient $\mathrm{CO}_{2}$ concentration $\left(\mathrm{C}_{\mathrm{i}} / \mathrm{C}_{\mathrm{a}}\right)$, and $\mathrm{SCO}$. In both experiments, significant QTLs for $\mathrm{A} / \mathrm{m}^{2}, A / \mathrm{m}^{2} 4.1 E 3\left(R^{2}=\right.$ $0.14)$ and $A / m^{2} 4.1 \_E 4\left(R^{2}=0.19\right)$ were identified in the same location on chromosome 4. These QTLs mapped within a cluster of QTLs associated with $\Delta^{13} \mathrm{C}$, SLA, LW, 
$I=10 \mathrm{cM}$
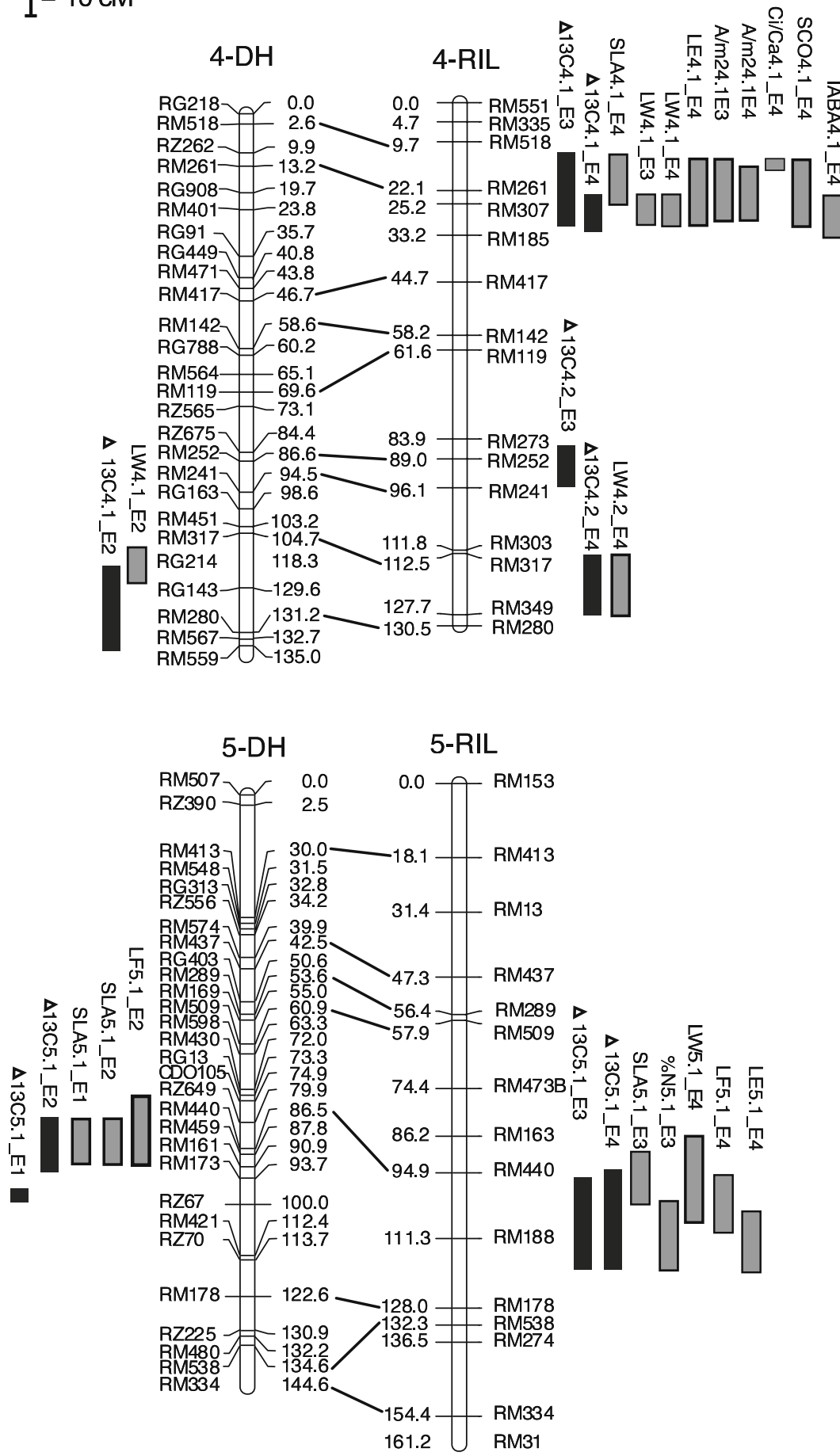

8-DH 8-RIL

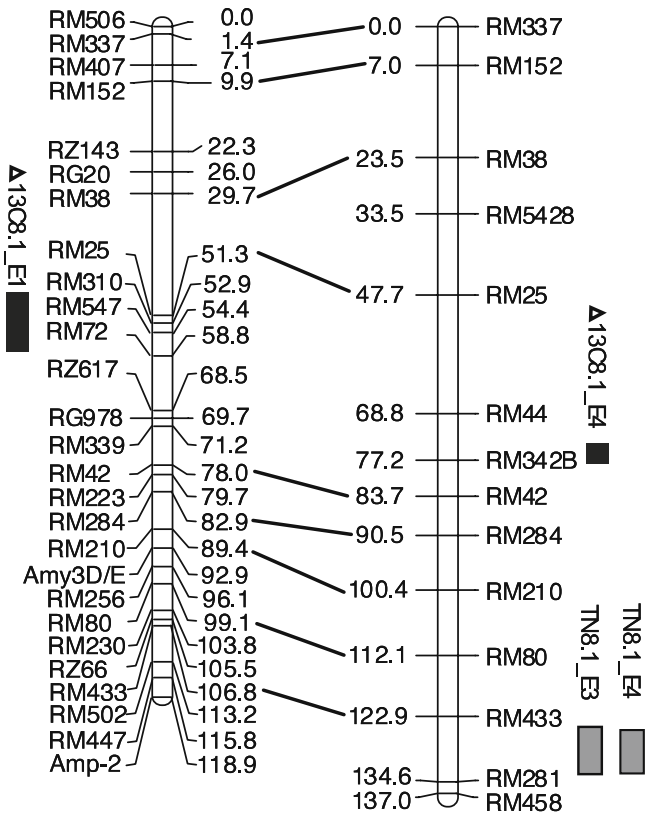

Fig. 2 Representation of QTL confidence intervals (peak LOD scores minus 1) on chromosomes 4, 5, and 8, with QTLs for carbon isotope discrimination $\left(\Delta^{13} \mathrm{C}\right)$ indicated by black rectangles and all others indicated by gray rectangles as follows: specific leaf area and percent nitrogen $(S L A$ and $\% N)$, leaf width $(L W)$, tiller number $(T N)$, leaf curling and leaf drooping ( $L C$ and $L D$ ), photosynthesis rate and ratio of plant $\mathrm{CO}_{2}$ concentration/air $\mathrm{CO}_{2}$ concentration $(\mathrm{A} / \mathrm{m} 2$ and $\mathrm{Ci} / \mathrm{Ca})$, stomatal conductance $(S C O)$, and logarithm of leaf ABA concentration measured in medium vapor pressure deficit $(l A B A)$. Chromosome maps for the IR64 $\times$ Azucena doubled haploid $(D H$, on left $)$ and recombinant inbred (RI, on right) populations were aligned based on common markers (indicated by connecting lines between pairs of maps). 
LD, $\mathrm{A} / \mathrm{m}^{2}, \mathrm{C}_{\mathrm{i}} / \mathrm{C}_{\mathrm{a}}, \mathrm{SCO}$, and 1ABA (Fig. 2). Azucena alleles increased $\mathrm{A} / \mathrm{m}^{2}$. At the same locus, the QTL $\mathrm{Ci} / \mathrm{Ca} 4.1 \_$E4 $\left(\mathrm{R}^{2}=0.08\right)$ was identified just below threshold, and SCO4.1_E4 was a QTL significant for stomatal conductance that explained $19 \%$ of the phenotypic variation, where alleles from Azucena increased SCO. Other small QTLs for $\mathrm{C}_{\mathrm{i}} / \mathrm{C}_{\mathrm{a}}$ were identified on chromosome 1 and on chromosome 2. Two of the alleles associated with high $\mathrm{C}_{\mathrm{i}} /$ $\mathrm{C}_{\mathrm{a}}$ came from Azucena, while for the QTL on chromosome 2 the allele associated with high $\mathrm{C}_{\mathrm{i}} / \mathrm{C}_{\mathrm{a}}$ came from IR64.

Abscisic acid In a first attempt to analyze hormonal influence on $\Delta^{13} \mathrm{C}$, leaf $\mathrm{ABA}$ concentration was measured a few days after collecting the physiological measurements in E4. The sampling was done on plants submitted to a moderate vapor pressure deficit (approximately $18 \mathrm{mbar}$ at a leaf temperature of $30^{\circ} \mathrm{C}$ ). Although the coefficient of variation of the trial was quite high, the genotype effect was highly significant. A significant QTL, lABA4.1_E4 $\left(R^{2}=\right.$ 0.07 ), was identified on chromosome 4 , in a region that contained a cluster of other previously described QTLs (Fig. 2). At this locus, IR64 alleles increased ABA concentrations. An additional QTL, lABA12.1_E3 $\left(R^{2}=\right.$ 0.13 ) was detected on chromosome 12, with Azucena alleles contributing to an increase in leaf ABA.

\section{Discussion}

Genetic inheritance of carbon isotope discrimination in rice and other species

Results of this study confirm that the genetic variation associated with carbon isotope discrimination in rice is inherited polygenically (Dingkuhn et al. 1991). The QTL with the largest effect on $\Delta^{13} \mathrm{C}$ explained more than $19 \%$ of the phenotypic variation. Although one study in Arabidopsis found a major QTL encoding the transcription factor, ERECTA, which explained up to $64 \%$ of the phenotypic variation in a Landsberg $\times$ Columbia RI population (Masle et al. 2005), studies evaluating genetic variation for carbon isotope discrimination in other plant species have identified multiple QTLs of smaller effect associated with the trait. For example, in another population of Arabidopsis, two to five QTLs were identified (Hausmann et al. 2005; Juenger et al. 2005). In rice, one to three QTLs for $\Delta^{13} \mathrm{C}$ were identified by Laza et al. (2006) and Takai et al. (2006), three to five by Price et al. (2002), and four by Xu et al. (2009). Up to seven QTLs were identified in Stylosanthes scabra (Thumma et al. 2001), two to five in barley (Diab et al. 2004; Ellis et al. 2002; Teulat et al. 2002), and four to five in Brassica oleracea (Hall et al.
2005). In these studies, individual QTLs explained $\leq 30 \%$ of the phenotypic variation for $\Delta{ }^{13} \mathrm{C}$, consistent with results from the present study. For three of the four genetic regions identified as controlling $\Delta^{13} \mathrm{C}$, QTLs were identified in both mapping populations. In the near-centromeric region for chromosome 4, however, QTLs were identified only for the RIL population. The failure to detect these QTLs in the DH population may be a result of a sampling bias related to the small size of this population or a lack of recombination in the corresponding region in the DH population, which could annul the QTL effect, possibly due to a cis-trans effect.

Effect of parental alleles associated with QTLs for $\Delta^{13} \mathrm{C}$ in rice

Although the parents in this study did not show significant differences for $\Delta^{13} \mathrm{C}$, transgressive variation in the segregating population provided sufficient range in $\Delta^{13} \mathrm{C}$ such that significant marker-trait associations were identified in both populations. Each of the parents contributed both positive and negative alleles to the trait, thereby providing an explanation for the underlying genetic basis of the transgressive variation observed among the segregants. Transgressive variation has been explained similarly in several other quantitatively inherited traits (deVicente and Tanksley 1993; Li et al. 2004; Reiseberg et al. 2003). Of the QTLs for $\Delta^{13} \mathrm{C}$, the favorable effect (decreased $\Delta^{13} \mathrm{C}$ and increased WUE) was associated with the IR64 parent for the QTLs on the short arm of chromosome 4 and on the long arm of chromosome 5, whereas the favorable effect was associated with the Azucena parent for the QTL on the long arm of chromosome 4.

QTLs for $\Delta^{13} \mathrm{C}$ on chromosomes 4 and 8 have been repeatable across multiple studies of rice involving different mapping populations and growing conditions. Price et al. (2002) used a recombinant inbred population derived from a cross between Bala (indica) and Azucena (tropical japonica), while Laza et al. (2006) used an RIL population from a cross of New Plant Type (tropical japonica) and IR72 (lowland indica) growing in irrigated lowland field sites. Both Price et al. (2002) and Laza et al. (2006) identified a QTL for grain $\Delta{ }^{13} \mathrm{C}$ on the long arm of chromosome 4 in the same large area as QTLs $\triangle 13 C 4.2 E$ E3 and $\triangle 13 C 4.2_{-} E 4$ in the current study. The japonica alleles increased the trait value in both studies. Also, the QTL we identified on chromosome $8(\Delta 13 C 8.1$ E1 and E4) colocalizes with a $\Delta^{13} \mathrm{C}$ QTL in the study from Laza et al. (2006), but the indica parent in that study (IR72) had the opposite effect compared to IR64, the indica used in our study. $\mathrm{Xu}$ et al. (2009) identified a QTL for $\Delta{ }^{13} \mathrm{C}$ in the same chromosomal region as $\Delta{ }^{13} \mathrm{C} 4.1 \mathrm{E} 3$ and $\Delta{ }^{13} \mathrm{C} 4.1 \mathrm{E} 4$, where the japonica (Nipponbare) allele increased $\Delta^{13} \mathrm{C}$ 
values compared to Kasalath, consistent with the effect of Azucena in the present study.

\section{Relationship between $\Delta{ }^{13} \mathrm{C}$ and leaf traits}

In this study, several aspects of plant morphology were associated with $\Delta^{13} \mathrm{C}$, including leaf width, leaf length, specific leaf area, and leaf erectness. Leaf width had a particularly strong association with $\Delta{ }^{13} \mathrm{C}$ as three QTL clusters associated with leaf width colocalized with QTLs for $\Delta^{13} \mathrm{C}$. Consistent with this, a few of the phenotypic correlations were significant, and they showed that increased leaf width was correlated with lower $\Delta^{13} \mathrm{C}$. A plausible explanation for the association would be that wider leaves have greater leaf-boundary-layer resistance to gaseous diffusion, which would have the tendency to lower the $\mathrm{C}_{\mathrm{i}} / \mathrm{C}_{\mathrm{a}}$ ratio and decrease $\Delta{ }^{13} \mathrm{C}$. Lhomme et al. (1992) suggested that, whereas boundary layer resistance is affected weakly by leaf width, wind velocity and leaf area index have a strong effect. Alternatively, other factors associated with leaf morphogenesis may be pleiotropic with leaf width, such as stomatal density or leaf thickness, and these may form the basis for the connection between leaf width and $\Delta^{13} \mathrm{C}$. In this study, QTLs for specific leaf area were also colocated with the QTL clusters on the short arm of chromosome 4 (containing $\Delta 13 C 4.1$ for E3 and E4) and chromosome 5 (containing $\triangle 13 C 5.1$ for E2, E3, and E4). In a study by Price et al. (2002), a QTL for SLA was identified under drought conditions in the Philippines that mapped to the region on chromosome 5 containing $\Delta^{13} \mathrm{C}$ QTLs in the present study. Laza et al. (2006) identified a QTL for SLA and $\% \mathrm{~N}$ on chromosome 5 in the same region, though they did not identify a QTL for $\Delta^{13} \mathrm{C}$ in that location. Although previous studies have identified a variety of associations between $\Delta^{13} \mathrm{C}$ and various leaf morphological traits, the current study is the first to identify leaf width as a strongly associated trait.

\section{Relationship between $\Delta{ }^{13} \mathrm{C}$ and phenology}

Plant phenology can be a confounding effect when evaluating plant response to drought, as developmental stage can affect greatly plant metabolism and hormonal regulation. To minimize the influence of plant development on our evaluation of $\Delta{ }^{13} \mathrm{C}$, this study was conducted at the vegetative stage, well before the plants entered the reproductive stage. Thus, no data on flowering time were recorded in our experiments. Nonetheless, QTLs controlling days to flowering have been identified in other mapping populations in the near-centromeric region of chromosome 4 and on chromosome 8 around C1121 (http:// www.gramene.org/). The significance of these flowering time QTLs in terms of their impact on the traits measured in this study or on the evolution of the regions of the rice genome containing QTLs associated with $\Delta{ }^{13} \mathrm{C}$ is not known at this time.

\section{Relationship between $\Delta^{13} \mathrm{C}$ and plant photosynthesis}

In this study, $\Delta{ }^{13} \mathrm{C}$ was used as a proxy for WUE based on the expected dependency of both parameters on $\mathrm{C}_{\mathrm{i}} / \mathrm{C}_{\mathrm{a}}$ (Farquhar et al. 1989; Farquhar and Richards 1984). The value of $\Delta^{13} \mathrm{C}$ lies in its robust integration of gas exchange behavior through time and its high heritability (Condon et al. 2004). This conclusion is supported in the current study by the high heritability of $\Delta^{13} \mathrm{C}$ measurements $(0.77$ to $0.85)$ and correlation across experiments $(r=0.62$ and 0.63 for E1 vs E2 and E3 vs E4, respectively) compared to lower values for $\mathrm{C}_{\mathrm{i}} / \mathrm{C}_{\mathrm{a}}$ determined from gas exchange measurements $(r=0.38)$. Also, the proportion of the variance explained by a QTL, as indicated by $R^{2}$ values, was higher for $\Delta^{13} \mathrm{C}\left(R^{2}=0.08-0.19\right)$ than for $\mathrm{C}_{\mathrm{i}} / \mathrm{C}_{\mathrm{a}}\left(R^{2}=0.07-0.08\right)$.

The demonstration that a given $\Delta^{13} \mathrm{C}$ QTL is actually identifying a WUE QTL requires supporting evidence from other techniques such as co-occurrence of significant $\Delta{ }^{13} \mathrm{C}$ and $\mathrm{C}_{\mathrm{i}} / \mathrm{C}_{\mathrm{a}}$ peaks in the QTL analysis. On the short arm of chromosome 4, there were significant QTL peaks for stomatal conductance and photosynthetic capacity, $\mathrm{C}_{\mathrm{i}} / \mathrm{C}_{\mathrm{a}}$ and $\Delta^{13} \mathrm{C}$ (Table 3 ), and we conclude that this is a true WUE QTL. However, gas exchange measurements were not significant at the other $\Delta^{13} \mathrm{C}$ QTLs identified in this study. This discrepancy may be due to the less reliable nature of the gas exchange measures or other genetic variation (like respiratory losses) acting on $\Delta{ }^{13} \mathrm{C}$ independently of $\mathrm{C}_{\mathrm{i}} / \mathrm{C}_{\mathrm{a}}$.

Phenotypic correlations indicated that variation in $\mathrm{C}_{\mathrm{i}} / \mathrm{C}_{\mathrm{a}}$ in these studies was primarily due to large variations in stomatal conductance rather than biochemical activities of the photosynthetic system. There was a strong positive correlation between $\mathrm{A}$ and $\mathrm{SCO}$, but the proportional range of variation in SCO was much greater than in A (Table 2), and this effect dominated patterns of $\mathrm{C}_{\mathrm{i}} / \mathrm{C}_{\mathrm{a}}$. Similar relationships were seen in our companion study on rice mapping populations derived from Kasalath $\times$ Nipponbare (Xu et al. 2009).

In the work on Arabidopsis by Masle et al. (2005), the ERECTA gene underlying a $\Delta^{13} \mathrm{C}$ QTL was associated with both stomatal limitations on photosynthesis and leaf photosynthetic capacity at saturating $\mathrm{CO}_{2}$. In Arabidopsis, when two NILs were compared to the Landsberg erecta wild type, a significant difference in stomatal conductance (and transpiration efficiency) was associated with $\Delta^{13} \mathrm{C}$ QTLs (Juenger et al. 2005). These authors suggested that the QTL alleles affected $\Delta^{13} \mathrm{C}$ through changes in stomatal control of $\mathrm{CO}_{2}$ diffusion to the leaf interior. Our results support this hypothesis with respect to the chromosome 4 
QTL cluster. Using chromosome segment substitution lines, Takai et al. (2009) also showed that a QTL region on chromosome 3 was associated with increased $\Delta{ }^{13} \mathrm{C}$ and enhanced SCO.

The observed variation in photosynthetic capacity could be related to positive correlations sometimes seen between $\mathrm{A}$ and $\% \mathrm{~N}$. Leaf $\% \mathrm{~N}$ was positively correlated with $\Delta{ }^{13} \mathrm{C}$ in all experiments, and \%N 5.1_E3 colocalized on chromosome 5 with QTLs for $\Delta^{13} \mathrm{C}$. Takai et al. (2006) similarly observed a colocalization between $\Delta^{13} \mathrm{C}$ and leaf $\% \mathrm{~N}$ on chromosome 1 . This suggests an underlying mechanism by which plants regulate their tradeoff between WUE and nitrogen use efficiency; stomatal conductance is adjusted to supply the photosynthetic system with sufficient $\mathrm{CO}_{2}$ to match its capacity, as affected by leaf $\mathrm{N}$ status, while water loss is kept within limits (Hausmann et al. 2005). The $\Delta^{13} \mathrm{C}$ QTL on the short arm of chromosome 4 that does not follow this rule could be based on a stomatal effect rather than an effect on photosynthetic biochemistry.

$\mathrm{ABA}$ is known to regulate stomatal aperture and gas exchange, particularly in water deficit conditions (Wilkinson and Davies 2002). In the current study, a significant QTL for ABA on chromosome 4 (lABA4.1_E4) colocalized with QTLs for $\Delta{ }^{13} \mathrm{C}, \mathrm{SCO}$, and $\mathrm{C}_{\mathrm{i}} / \mathrm{C}_{\mathrm{a}}$. Given that the current study kept soil well supplied with water and atmospheric humidity was relatively mild, transpiration-related stress would have been relatively limited under our growth and measurement conditions. However, although the range was small, there was some variation in leaf water status in experiment $\mathrm{E} 4$, as measured by relative water content, suggestive of genetic differences in baseline concentrations of ABA in minimally stressed plants or sensitivities to factors that regulate ABA homeostasis. In rice and numerous other species, evidence from mutants that are defective in $\mathrm{ABA}$ synthesis or components of $\mathrm{ABA}$ signaling indicates that $\mathrm{ABA}$ plays a role in stomatal regulation even in environments that are not stressful for wild types (Agrawal et al. 2001; Taylor et al. 2005). ABA levels were negatively correlated with stomatal conductance, $\mathrm{C}_{\mathrm{i}} / \mathrm{C}_{\mathrm{a}}$, and $\Delta{ }^{13} \mathrm{C}$ in the overall RIL mapping population, consistent with the expected effect of $\mathrm{ABA}$ in closing stomata and a functional link between these traits.

An additional factor that can affect the approach to zero turgor, which initiates ABA synthesis, is the osmotic solute concentration in a tissue (Xiong and Zhu 2003). A higher solute concentration will allow cells at similar RWC to decline to a lower water potential, such as during high midday transpiration, before turgor is lost. A previous study of rice found a QTL for osmotic adjustment on the short arm of chromosome 4 that colocalizes with the current QTL for $\Delta{ }^{13} \mathrm{C}$ (Robin et al. 2003). Hence, it is plausible that the clustering of QTL on the short arm of chromosome 4 could be mechanistically linked through the several factors examined here that affect solute and turgor water status: $\mathrm{ABA}$, stomatal conductance, $\mathrm{C}_{\mathrm{i}} / \mathrm{C}_{\mathrm{a}}$, and $\Delta^{13} \mathrm{C}$.

It is also possible that the QTLs for $\Delta^{13} \mathrm{C}$ identified on chromosomes 8 and 5 and for ABA on chromosome 12 are linked to osmotic solute status. At a position corresponding to the QTL for $\Delta^{13} \mathrm{C}$ found on chromosome 8, several groups working on rice have found a QTL for osmotic adjustment (Kamoshita et al. 2002; Robin et al. 2003; Zhuang et al. 2002). At the orthologous position corresponding to the QTL for $\Delta{ }^{13} \mathrm{C}$ on rice chromosome 5 , barley has a QTL for osmotic solute potential and watersoluble carbohydrates (associated with RFLP marker CDO202) on chromosome $1 \mathrm{H}$ (Diab et al. 2004). The position of the ABA QTL (IABA12.1_E3) on rice chromosome 12 is orthologous to a region of barley chromosome $2 \mathrm{H}$ where two QTLs for $\Delta^{13} \mathrm{C}$ and a QTL for osmotic adjustment were identified (Teulat et al. 2002) and to the homologous wheat chromosomes $2 \mathrm{~A}$ and $2 \mathrm{~B}$ where a QTL for osmotic solute potential was found (Diab et al. 2004). In our case, no QTL for $\Delta{ }^{13} \mathrm{C}$ colocalized with the QTL for ABA concentration on rice chromosome 12 (IABA12.1_E3), but the ABA QTL in our study appears to be in a homologous position with a QTL for $\Delta^{13} \mathrm{C}$ found by Laza et al. (2006) in irrigated lowland rice.

Further study will be required to determine the extent to which osmotic adjustment or hydraulic conductance is involved in genetic effects on this process and their link with $\Delta^{13} \mathrm{C}$.

Perspectives for marker-assisted selection in rice breeding for an improved water use efficiency

Our results highlight the near-centromeric region of chromosome 4 as an interesting region for marker-assisted selection because of the colocalization of several QTLs that form a rational link between leaf water status (turgor) and stomatal regulation by ABA of water loss and $\mathrm{C}_{\mathrm{i}} / \mathrm{C}_{\mathrm{a}}$. At this locus, improved water use efficiency would come from the indica variety IR64. However, the long arm of the same chromosome contains QTL acting in opposite directions; therefore, recombination between the two chromosomal regions would be required as a first target for markerassisted selection.

The colocalization of QTLs for $\Delta^{13} \mathrm{C}$ along with diverse shoot traits is noteworthy, and it is consistent with observations by plant breeders who note that early seedling vigor (involving both shoot and root growth) is critical to improving the water use efficiency and overall agronomic performance of cereals (Condon et al. 2004). Interestingly, leaf width is often used as an indirect selection tool for embryo size, a trait that is consistently associated with seedling vigor and water use efficiency in the cereals (Condon et al. 2004). In our study, leaf width was 
genetically correlated with all three of the $\Delta^{13} \mathrm{C}$ QTL clusters on chromosomes 4 and 5, as QTLs for these traits colocalized at all three sites. Phenotypic correlations indicated that low $\Delta \Delta^{13} \mathrm{C}$ is associated with wider leaves. The colocalization of QTLs for $\Delta{ }^{13} \mathrm{C}$, leaf width, and specific leaf area suggests that the factors controlling $\Delta^{13} \mathrm{C}$ are genetically and possibly physiologically linked to those governing overall plant growth and development. If this is true, selection for increased water use efficiency in rice is likely to be associated with visible phenotypic and morphological features.

Condon et al. (2004) reported the release of a new wheat variety with high yield performance in water-limited environments after a breeding process in which selection for low $\Delta^{13} \mathrm{C}$ in unstressed plants led to high WUE. Moreover, Rebetzke et al. (2008) suggested that for wheat, after removal of height and developmental effects, variation in carbon isotope discrimination was associated with a very small genetic effect on harvest and grain yield. Given the cost of $\Delta^{13} \mathrm{C}$ analysis, there is interest in identifying less expensive, well-correlated traits that could act as surrogate traits for selection. The current study indicates that, in rice, selection for leaf width may be worth considering for use in initial screens to enhance WUE. This merits further investigation in additional populations. Screening for global seedling vigor may prove to be also a good approach for enhancing water use efficiency.

An understanding of the genes and the molecular mechanisms that condition this complex phenotype in rice will provide new possibilities for applications in plant breeding and will also offer fundamental insights into one of the basic physiological processes that governs plants' ability to regulate access to $\mathrm{CO}_{2}$ while avoiding excess water loss.

\section{Materials and methods}

\section{Mapping populations}

Two rice (Oryza sativa L.) populations were used in this project: both represent segregating populations derived from a cross between cv. Azucena (tropical japonica) and cv. IR64 (indica). One was a DH population consisting of $91 \mathrm{DH}$ lines, and the other was a RI population consisting of 165 RI lines generated by single seed descent.

Genotyping and map construction

A genetic map for the DH population used in this study was initially published by (Huang et al. 1994), and SSR markers were added to increase the resolution of this framework map (Temnykh et al. 2000). For this study, we obtained segregation data from 395 framework markers published by Temnykh et al. (2000) and used them to recalculate genetic distances using MapManager QXTb20 software (Manly et al. 2001). These markers were used to construct a genetic map consisting of $1,836 \mathrm{cM}$ (Kosambi function) for the $\mathrm{DH}$ population. For the RI population, segregation data for 180 SSRs were generated in Agropolis, Montpellier, as part of a global comparative mapping project on the IR64 $\times$ Azucena cross (Ahmadi et al. 2005), and 40 additional SSR markers were mapped onto this population at Cornell University over the course of this project to provide correspondences with the DH population map. Common genetic loci were used to define syntenic regions between the two maps at a macroscopic scale.

\section{Experimental design}

Four experiments (named E1, E2, E3, and E4) were conducted in the greenhouses at the Boyce Thompson Institute (Ithaca, USA) between January and December 2003, under well-watered conditions. Experiments 1 and 2 were conducted with the $\mathrm{DH}$ population and experiments 3 and 4 with the RI population. Each experiment was a randomized complete block design with two replications. The experimental unit consisted of one plant per replication. The number of plants per parental control was two in $\mathrm{E} 1$ and E2, 15 in E3, and 40 in E4. Phenotypic data were collected 25 days after sowing plants in 2-1 pots for E1, E2, and $\mathrm{E} 3$ and 40 days after sowing for E4.

Environmental variation associated with phenotypic evaluation

Table 1 summarizes the experimental conditions for all four experiments. Greenhouse bays were individually monitored to document consistency of light, $\mathrm{RH},\left[\mathrm{CO}_{2}\right]$, and air temperature. The first two experiments (E1 and E2), in which we evaluated the DH population, experienced a relatively high light intensity (mean of the experiment between 1,168 and $1,147 \mu \mathrm{mol} / \mathrm{m}^{2}$ per second), while the last two experiments (E3 and E4) evaluating the RI population experienced a medium light intensity (mean of the experiment between 687 and $743 \mu \mathrm{mol} / \mathrm{m}^{2}$ per second). Variation in high-intensity discharge (HID) lamp output was measured at each plant position, and these values, when collected, were entered into preliminary statistical analyses as a covariate, and adjusted data were calculated prior to analyses of variances and mean computations. These effects were always small but consistently significant for $\Delta^{13} \mathrm{C}$ in particular.

Air temperature was lower in E1 compared to the other experiments. Based on experimental $\mathrm{CO}_{2}$ concentrations in the greenhouses measured for all experiments, $\delta^{13} \mathrm{C}$ of the air ranged between $-7.81 \%$ (E4) and $-9.17 \%$ (E1). 
Morphological measurements

LL and LW and the TN initiated were measured just prior to sampling for isotope analysis. The length of the largest leaf on each plant was measured from soil surface to tip and thus includes both blade and sheath portions. Width was taken at the widest point (middle) of the same leaves. Tillers were counted if over $2 \mathrm{~cm}$ long.

The cross-sectional leaf shape differed among lines, with some having flat planar leaf surfaces and others having a distinct upward fold at the midrib, producing a concave, triangular-channeled shape at the abaxial surface. LF was evaluated on a scale of 1 (flattest) to 3 (most channeled) in the $\mathrm{DH}$ population in $\mathrm{E} 2$ and from 1 to 5 in the RI population in E4.

Leaf shape was also evaluated in terms of leaf stiffness and posture. LE was evaluated based on whether the tip was held fully erect, bent to horizontal, or pointing downward, using a scale of 1 (most erect) to 3 (most recurved) in E2 and 1 to 5 in E4.

\section{Shoot biomass}

Residual above-ground biomass was harvested immediately following isotope sampling in E1 and E2. This biomass was dried in a forced convection oven at $60^{\circ} \mathrm{C}$ for $96 \mathrm{~h}$ and then weighed. SB was the sum of residual shoot, isotope sample, and RWC sample weights.

\section{Isotopic analysis}

$\Delta^{13} \mathrm{C}$ was evaluated as described in Comstock et al. (2005) using a Finnigan Matt Delta Plus isotope ratio mass spectrometer at the Cornel Stable Isotope Laboratory (COIL). Isotope ratio data were provided by COIL relative to the IAEA standard PDB, as:

$$
\delta^{13} C=\left(\frac{\frac{13}{12} \text { sample }}{\frac{13}{12} \text { standard }}-1\right) \times 1000, \%
$$

$\delta^{13} \mathrm{C}$ was measured for plant samples from each experiment, and $\Delta^{13} \mathrm{C}$ was calculated as:

$$
\Delta^{13} C=\frac{\delta^{13} C_{\text {air }}-\delta^{13} C_{\text {plant }}}{1+\frac{\delta^{13} C_{\text {plant }}}{1000}}, \%
$$

The evaluation of $\delta^{13} \mathrm{C}$ of atmospheric $\mathrm{CO}_{2}$ was measured directly only at the beginning of the project to establish a relationship between $\delta^{13} \mathrm{C}_{\text {air }}$ and $1 /\left[\mathrm{CO}_{2}\right]$ (Keeling 1958) in the growth facility. In each experiment reported here, atmospheric $\left[\mathrm{CO}_{2}\right]$ was measured continuously in each greenhouse bay throughout the growth interval, and mean $\left[\mathrm{CO}_{2}\right]$ from the week preceding sampling was converted to an estimate of $\delta^{13} \mathrm{C}_{\text {air }}$ using

$$
\delta^{13} C_{\text {air }}=4429 \times \frac{1}{\left[\mathrm{CO}_{2}\right]}-21.45, \% \text { o }
$$

Leaves for isotopic analyses were chosen from the youngest cohort of leaves that had completed the phase of rapid expansion. These represented the largest leaves on the young vegetative plants and occupied upper canopy positions experiencing maximal illumination. Two full leaf blades from each of two or more tillers per 3-4-week-old rice plant were sampled. After drying, $48 \mathrm{~h}$ at $60^{\circ} \mathrm{C}$, leaf samples were ground into a homogeneous powder, and 2-mg subsamples were weighed for isotopic analysis. In addition to $\delta^{13} \mathrm{C}$, COIL analyses provided elemental composition in $\%$ $\mathrm{N}$, with measurement precisions of $\pm 0.1 \%$ and $\pm 0.1 \%$, respectively.

\section{Relative water content}

RWC was measured on leaf sections from the same leaves used for isotopic analysis (experiment E4 only) according to Turner (1981). A 6-cm segment was excised from the middle of the leaf blade, and its fresh weight was immediately taken. Segments were floated $24 \mathrm{~h}$ on pure water in a Petri dish and reweighed after gently blotting away surface moisture (TW). A third weight was taken after drying in a forced convection oven at $60^{\circ} \mathrm{C}$ for $48 \mathrm{~h}$. RWC was calculated as:

$\mathrm{RWC}=\frac{\mathrm{FW}-\mathrm{DW}}{\mathrm{TW}-\mathrm{DW}} \times 100$

Specific leaf area

SLA was defined as projected leaf area per gram dry weight. The same samples used for isotopic analysis were passed through a LICOR 3200 leaf area meter at the time of harvest. They were weighed after $48 \mathrm{~h}$ in a forced convection oven at $60^{\circ} \mathrm{C}$ prior to grinding for isotopic analysis.

\section{Gas exchange}

Leaf photosynthetic gas exchange was measured on the entire QTL mapping populations in E3 (one replication per line) and E4 using a LICOR 6400 portable photosynthesis system. Leaf gas exchange was measured on plants in the 
greenhouse at a station that provided extra HID lighting. Plants were situated under a heat shield provided by circulating water in a suspended $1 \times 2 \times 0.1 \mathrm{~m}$ Plexiglas tray to ensure that all plants were uniformly exposed to high light intensities similar to bright midday conditions in their normal growth positions (approximately 1,000 $\mu \mathrm{mol}$ (PAR) $\mathrm{m}^{-2} \mathrm{~s}^{-1}$ ) regardless of time of day or transient weather conditions, while still experiencing typical temperatures and humidities for the growth environment. This allowed rapid measurement of light-saturated rates of photosynthesis on target leaves while maintaining normal whole-plant activity. Each measurement included an 8-min adjustment period to the cuvette conditions.

\section{Leaf ABA measurement}

In experiments $\mathrm{E} 3$ and $\mathrm{E} 4$, leaf disks $\left(2.5 \mathrm{~cm}^{2}\right)$ were cut from leaves and put into ice-cold $80 \%$ methanol $(v / v)$ and stored at $-20^{\circ} \mathrm{C}$. ABA was exodiffused at $24^{\circ} \mathrm{C}$; extracts were transferred to new tubes and dried in vacuo. Extracts were fractionated by $\mathrm{C} 18$ reverse-phase solid phase extraction. Dried extracts were reconstituted in $100 \mu$ of $30 \%(v / v)$ acidified methanol solution (30\% methanol, $69 \%$ distilled water, $1 \%$ glacial acetic acid), and $8 \mu \mathrm{g}$ Bromocresol green was added as a chromatograph tracer. Extracts were loaded onto C18 columns (model: DSC-18, $25 \mathrm{mg}$ packing material, Supelco, Bellefonte, PA, USA), and solvents were drawn through the columns under vacuum to provide flow rates of about $50 \mu \mathrm{l} / \mathrm{min}$ or less. Hydrophilic substances were removed by elution of the loaded $30 \%$ methanol and washing with an additional $320 \mu \mathrm{l}$ of $30 \%$ methanol. ABA was eluted with $200 \mu \mathrm{l}$ of $65 \%$ methanol. ABA fractions were alkalinized with $\mathrm{NH}_{4} \mathrm{OH}$, and absorbance of Bromocresol green was read at $590 \mathrm{~nm}$. Absorbance data indicated that less than $10 \%$ of the tracer was lost by channeling at the $30 \%$ methanol steps; data were corrected for these losses. ABA fractions were dried in vacuo and stored at $-20^{\circ} \mathrm{C}$. Samples were redissolved in $100-\mu \mathrm{l}$ distilled water, and $10-\mu \mathrm{l}$ aliquots were analyzed by enzyme-linked immunosorbent assay for ABA as previously described (Melkonian et al. 2004).

\section{Statistical analysis}

Analyses of variance were performed to check the existence of genetic variation among the lines independently for the four experiments on all the measured traits. The measurements with no significant genotypic effect were not included in further analyses. For all the other traits, adjusted means were computed. The broad sense heritabilities were then computed from the estimates of genetic $\left(\sigma^{2} \mathrm{G}\right)$ and residual $\left(\sigma^{2} \mathrm{e}\right)$ variances derived from the expected mean squares of the analyses of variances as $h^{2}=\sigma^{2} \mathrm{G} /$ $\left(\sigma^{2} \mathrm{G}+\sigma^{2} \mathrm{e} / k\right)$ where $k$ was the number of replications. The phenotypic correlations between years and traits were computed using the genotype means from the individual trials. For the two pairs of trials (E1 and E2; E3 and E4), analyses of variance were performed to assess the extent of the genotype $\times$ trial interactions. All analyses were conducted with SAS v. 9.1.

\section{QTL analysis}

QTLs were identified with Windows QTL cartographer V.2 (Wang et al. 2006) by composite interval mapping (CIM) using the standard model, with a backward and forward regression to generate background markers. The "in" and "out" probability was 0.01. Empirical likelihood ratios were generated by running 1,000 permutations for each trait individually, giving LOD threshold values ranging between 3.03 and 3.45. In addition, single marker and interval analysis were conducted, and some QTLs that failed to reach the empirical LOD threshold by CIM but that showed a highly significant effect on the trait by ANOVA are indicated as potential QTL. Left and right borders indicate confidence intervals at LOD max minus 1 . Positive additive values indicate an increased effect from Azucena.

Acknowledgements This work was supported by the National Science Foundation (Plant Genome Project Grant DBI-0110069, "Genomic Analysis of Plant Water Use Efficiency").

\section{References}

Agrawal GK, Yamazaki M, Kobayashi M, Hirochika R, Miyao A, Hirochika H. Screening of the rice viviparous mutants generated by endogenous retrotransposon Tos 17 insertion. Tagging of a zeaxanthin epoxidase gene and a novel ostatc gene. Plant Physiol. 2001;125:1248-57.

Ahmadi N, Dubreuil-Tranchant C, Courtois B, Fonceka D, This D, McCouch S, Lorieux M, Glasmann JC, Ghesquiere A. New resources and integrated maps for IR64 $\times$ Azucena: a reference population in rice. In IRRI, ed, 5th International Rice Genetics symposium. International Rice Research Institute, Manila, 2005.

Brendel O, Pot D, Plomion C, Rozenberg P, Guehl JM. Genetic parameters and QTL analysis of delta C-13 and ring width in maritime pine. Plant Cell Environ. 2002;25:945-53.

Casasoli M, Pot D, Plomion C, Monteverdi M, Barreneche T, Lauteri $\mathrm{M}$, et al. Identification of QTLs affecting adaptive traits in Castanea sativa Mill. Plant Cell Environ. 2004;27:1088-101.

Comstock JP, McCouch SR, Martin BC, Tauer CG, Vision TJ, Xu Y, et al. The effects of resource availability and environmental conditions on genetic rankings for carbon isotope discrimination during growth in tomato and rice. Funct Plant Biol. 2005;32:1089-105.

Condon AG, Richards RA, Rebetzke GJ, Farquhar GD. Breeding for high water-use efficiency. J Exp Bot. 2004;55:2447-60.

deVicente MC, Tanksley SD. QTL analysis of transgressive segregation in an interspecific tomato cross. Genetics. 1993;134:585-96. 
Diab A, Teulat-Merah B, This D, Ozturk N, Benscher D, Sorrells M. Identification of drought-inducible genes and differentially expressed sequence tags in barley. Theor Appl Genet. 2004;109:1417-25.

Dingkuhn M, Farquhar GD, De Datta SK, O'Toole JC. Discrimination of ${ }^{13} \mathrm{C}$ among upland rices having different water use efficiencies. Australian J Ag Res. 1991;42:1123-31.

Ellis RP, Forster BP, Gordon DC, Handley LL, Keith RP, Lawrence P, et al. Phenotype/genotype associations for yield and salt tolerance in a barley mapping population segregating for two dwarfing genes. J Exp Bot. 2002;53:1163-76.

Farquhar GD, Richards RA. Isotopic composition of plant carbon correlates with water use efficiency of wheat genotypes. Australian J Ag Res. 1984;11:539-52.

Farquhar GD, Ehleringer JR, Hubick KT. Carbon isotope discrimination and photosynthesis. Annu Rev Plant Physiol Plant Mol Biol. 1989;40:503-37.

Gleick PH. Water use. Annu Rev Environ Resour. 2003;28:275-314.

Hall NM, Griffiths H, Corlett JA, Jones HG, Lynn J, King GJ. Relationships between water-use traits and photosynthesis in Brassica oleracea resolved by quantitative genetic analysis. Plant Breed. 2005;124:557-64.

Hausmann NJ, Juenger TE, Sen S, Stowe KA, Dawson TE, Simms EL. Quantitative trait loci affecting delta ${ }^{13} \mathrm{C}$ and response to differential water availability in Arabidopsis thaliana. Evolution Int J Org Evolution. 2005;59:81-96.

Huang N, McCouch S, Mew TW, Parco A, Magpantay G. Development of an RFLP map from a doubled haploid population in rice. Rice Genet Newslett. 1994;11:134-7.

Juenger TE, McKay JK, Hausmann N, Keurentjes J, Sen S, Stowe $\mathrm{KA}$, et al. Identification and characterization of QTL underlying whole-plant physiology in Arabidopsis thaliana: delta C-13, stomatal conductance and transpiration efficiency. Plant Cell Environ. 2005;28:697-708.

Kamoshita A, Zhang J, Siopongco J, Sarkarung S, Nguyen HT, Wade LJ. Effects of phenotyping environment on identification of quantitative trait loci for rice root morphology under anaerobic conditions. Crop Sci. 2002;42:255-65.

Keeling CD. The concentration and isotopic abundances of atmospheric carbon dioxide in rural areas. Geochim Cosmochim Acta. 1958; $13: 322-34$

Laza MR, Kondo M, Ideta O, Barlaan E, Imbe T. Identification of quantitative trait loci for delta ${ }^{13} \mathrm{C}$ and productivity in irrigated lowland rice. Crop Sci. 2006;46:763-73.

Lhomme JP, Katerji N, Bertolini JM. Estimating sensible heat flux from radiometric temperature over crop canopy. Bound-Lay Meteorol. 1992;61:287-307.

Li J, Xiao J, Grandillo S, Jiang L, Wan Y, Deng Q, et al. QTL detection for rice grain quality traits using an interspecific backcross population derived from cultivated Asian $(O$. sativa L.) and African (O. glaberrima S.) rice. Genome. 2004;47:697-704.

Manly KF, Cudmore Jr RH, Meer JM. Map Manager QTX, crossplatform software for genetic mapping. Mamm Genome. 2001;12:930-2.

Martin B, Nienhuis J, King GJ, Schaefer A. Restriction fragment length polymorphisms associated with water-use efficiency in tomato. Science. 1989;243:1725-8.

Masle J, Gilmore SR, Farquhar GD. The ERECTA gene regulates plant transpiration efficiency in Arabidopsis. Nature. 2005;436: 866-70.

Melkonian J, Yu LX, Setter TL. Chilling responses of maize (Zea mays L.) seedlings: root hydraulic conductance, abscisic acid, and stomatal conductance. J Exp Bot. 2004;55:1751-60.

Price AH, Cairns JE, Horton P, Jones HG, Griffiths H. Linking drought-resistance mechanisms to drought avoidance in upland rice using a QTL approach: progress and new opportunities to integrate stomatal and mesophyll responses. J Exp Bot. 2002;53:989-1004.

Rebetzke G, Condon A, Farquhar G, Appels R, Richards R. Quantitative trait loci for carbon isotope discrimination are repeatable across environments and wheat mapping populations. Theor Appl Genet. 2008;118:123-37.

Reiseberg LH, Widmer A, Arntz AM, Burke JM. The genetic architecture necessary for transgressive segregation is common in both natural and domesticated populations. Philos Trans Soc Lond. 2003;358:1141-7.

Robin S, Pathan MS, Courtois B, Lafitte R, Arandang SC, Lanceras S, et al. Mapping osmotic adjustment in an advanced back-cross inbred population of rice. Theor Appl Genet. 2003;107:1288-96.

Saranga Y, Jiang C-X, Wright RJ, Yakir D, Paterson AH. Genetic dissection of cotton physiological responses to arid conditions and their inter-relationships with productivity. Plant Cell Environ. 2004;27:263-77.

Scalfi M, Troggio M, Piovani P, Leonardi S, Magnaschi G, Vendramin GG, et al. A RAPD, AFLP and SSR linkage map, and QTL analysis in European beech (Fagus sylvatica L.). Theor Appl Genet. 2004; 108:433-41.

Specht JE, Chase K, Macrander M, Graef GL, Chung J, Markwell JP, et al. Soybean response to water: a QTL analysis of drought tolerance. Crop Sci. 2001;41:493-509.

Takai T, Fukuta Y, Sugimoto A, Shiraiwa T, Horie T. Mapping of QTLs controlling carbon isotope discrimination in the photosynthetic system using recombinant inbred lines derived from a cross between two different rice (Oryza sativa L.) cultivars. Plant Prod Sci. 2006;9:271-80.

Takai T, Ohsumi A, San-oh Y, Laza M, Kondo M, Yamamoto T, et al. Detection of a quantitative trait locus controlling carbon isotope discrimination and its contribution to stomatal conductance in japonica rice. Theor Appl Genet. 2009;118:1401-10.

Taylor IB, Sonneveld T, Bugg TDH, Thompson AJ. Regulation and manipulation of the biosynthesis of abscisic acid, including the supply of xanthophyll precursors. J Plant Growth Regul. 2005;24:253-73.

Temnykh S, Park WD, Ayres N, Cartinhour S, Hauck N, Lipovich L, et al. Mapping and genome organization of microsatellite sequences in rice (Oryza sativa L.). Theor Appl Genet. 2000;100:697-712.

Teulat B, Merah O, Sirault X, Borries C, Waugh R, This D. QTLs for grain carbon isotope discrimination in field-grown barley. Theor Appl Genet. 2002;106:118-26.

Thumma BR, Naidu BP, Chandra A, Cameron DF, Bahnisch LM, Liu CN. Identification of causal relationships among traits related to drought resistance in Stylosanthes scabra using QTL analysis. J Exp Bot. 2001;52:203-14.

Turner NC. Correction of flow resistances of plants measured from covered and exposed leaves. Plant Physiol 1981;68:1090-1092.

Wang S, Basten CJ, Zeng Z-B. Windows QTL Cartographer 2.5. In, Ed 2.5. Dept. of Statistics, North Carolina State University, Raleigh, NC, 2006.

Wilkinson S, Davies WJ. ABA-based chemical signalling: the coordination of responses to stress in plants. Plant Cell Environ. 2002;25:195-210.

Xiong LZ, Zhu JK. Regulation of abscisic acid biosynthesis. Plant Physiol. 2003;133:29-36.

Xu Y, This D, Pausch R, Vonhof W, Coburn J, Comstock J, et al. Leaf-level water use efficiency determined by carbon isotope discrimination in rice seedlings: genetic variation associated with population structure and QTL mapping. Theor Appl Genet. 2009;118:1065-81.

Zhuang JY, Fan YY, Rao ZM, Wu JL, Xia YW, Zheng KL. Analysis on additive effects and additive-by-additive epistatic effects of QTLs for yield traits in a recombinant inbred line population of rice. Theor Appl Genet. 2002;105:1137-45. 